\title{
Multiple characterization study on porosity and pore structure of calcium phosphate cements
}

David Pastorino $^{1,2}$, Cristina Canal ${ }^{1,2}$, Maria-Pau Ginebra ${ }^{1,2}$ *

${ }^{1}$ Biomaterials, Biomechanics and Tissue Engineering Group, Department of Materials Science and Metallurgy, Universitat Politècnica de Catalunya. BarcelonaTech (UPC), Av. Diagonal 647, 08028 Barcelona, Spain

${ }^{2}$ Centre for Research in Nanoengineering, Technical University of Catalonia (UPC) c/Pascual i Vila 15, 08028 Barcelona, Spain

david.pastorino@upc.edu; cristina.canal@upc.edu ; maria.pau.ginebra@upc.edu

*Corresponding author:

Maria-Pau Ginebra

Biomaterials, Biomechanics and Tissue Engineering Group

Department of Materials Science and Metallurgical Engineering

Universitat Politècnica de Catalunya. BarcelonaTech (UPC)

Av. Diagonal 647, 08028 Barcelona, Spain

Telephone: +34 934017706, Fax: +34934016706

E-mail: maria.pau.ginebra@upc.edu 


\begin{abstract}
Being able to thoroughly characterize the intricate pore structure of calcium phosphate cements is a key step to successfully link the structural properties of these synthetic bone grafts with their most relevant properties, such as in vitro or in vivo behaviour, drug loading and release properties or degradation over time. This is a challenging task, due to the wide range of pore sizes compared to most other ceramic biomaterials. This work provides a critical assessment of three different techniques based on different physical phenomena, namely Mercury Intrusion Porosimetry (MIP), Nitrogen sorption and Thermoporometry (TPM) for the detailed characterization of four calcium phosphate cements with different textural properties, in terms of total porosity, Pore Size Distribution (PSD) and Pore Entrance Size Distribution (PESD). MIP had the advantage of covering a much wider size range than TPM and Nitrogen sorption, offering a more comprehensive information at the micrometric level. TPM, and specially Nitrogen sorption, besides being non-destructive techniques, and although covering a limited size range, provided complementary information regarding pore structure associated to crystal shape at the nanoscale, recording both PSD and PESD in a single experiment. MIP tended to register smaller sizes, especially at low L/P ratios, due to the network effect, that has a strong influence on the outcome of this technique.
\end{abstract}




\section{Introduction}

Porosity has become a key player in the design of biomaterials for bone regeneration. It is fully recognized that some crucial aspects, like the rate of resorption and the extent of tissue colonization depend not only on the intrinsic properties of the material, but also on the amount, size and shape of the pores included in the biomaterial $[1,2]$. The relevance of porosity is even higher when the material is designed to act, in addition, as a substrate for the local and controlled delivery of drugs or cells, since its performance will depend on some physical phenomena, like permeability or diffusion, which are directly linked to porosity [3]. But not only total porosity is important, the physical and biological behaviour of a porous material are strongly affected by the way in which the pores of various sizes are distributed within the solid. Hence, the importance of having a thorough characterization of the porosity and textural properties of the material, covering the full scale range. Whereas this can be relatively straightforward in the case of high-temperature sintered ceramics, the situation becomes more complex in biomimetic calcium phosphate materials, where nanometric crystals are obtained, with intricate microstructures and high specific surface area [4].

Calcium phosphate cements (CPCs) are a good example of nanostructured calcium phosphates $[4,5]$. These synthetic bone substitutes present attractive properties such as similarity to the mineral phase of bone, capacity to harden within the body or injectability. Once hardened, the material consists of a network of nanometric and micrometric precipitated crystals, which generate a high intrinsic micro/nano porosity, with a very wide pore size range, from $1 \mathrm{~nm}$ to $1 \mathrm{~mm}$, i.e. six orders of magnitude [6,7]. This allows designing materials inspired in the nanostructured nature of native bone $[4,7]$, with distinct advantages in terms of bioactivity, resorbability, permeability or the adsorption and release of active principles $[3,4,5,8,9]$. Despite this, their intrinsic 
complexity makes the detailed evaluation of the porosity of calcium phosphate cements a challenging task, the selection of the most adequate method for its characterization being not trivial.

Pycnometry, based on the Archimedes principle, can be used to determine the total pore volume, but it provides only limited or no information on pore structure parameters, like pore size distribution and specific surface area.

Mercury intrusion porosimetry (MIP) has proven to be a powerful technique to characterize porous materials with pore sizes ranging several orders of magnitude [10]. MIP is based on the intrusion of a non-wetting liquid, mercury into a material, and the possibility of relating the pressure needed to force mercury into the specimen with the equivalent pore sizes [11]. MIP is the most widely used method for determining the pore size distribution of hardened cement pastes for civil engineering applications, and it has also been successfully applied to the characterization of CPCs [5]. However, some concerns have been raised recently [12-14] related to the ink-bottle effect [15] and the high pressures applied which are speculated to be potentially harmful for the material. Moreover, a drying step is required prior to the experiment, which might affect its outcome. Other drawbacks are related to the toxicity of mercury, and to the fact that it is a destructive method, since the sample cannot be reused after part of the mercury remains irreversibly trapped in the pores.

An alternative technique is gas adsorption, which is one of the most popular methods for the study of pore structure in materials that contain micropores $(<2 \mathrm{~nm})$ and mesopores (between 2 and $50 \mathrm{~nm}$ ). In the field of CPCs, however, it has generally been limited to the characterization of the specific surface area $[1,16-18]$, using the Brunauer-Emmet-Teller (BET) theory [19], which involves a model for the adsorption 
of a monolayer of gas onto the surface of a material. However, capillary condensation measurements allow also to correlate vapour pressure and pore dimensions, providing information on pore size distribution in the material.

Thermoporometry (TPM), also called thermoporosimetry, is another method, based on the decrease of the freezing point of a probe liquid when confined in the pores of the material tested. The method, which was first described by Brun and Lallemand, allows correlating the shifts of the freezing and melting points with the pore size distribution of the material [21]. One of the main advantages of TPM is that, unlike most other techniques, it allows characterising wet samples, and there is no need for specialized instruments, since a differential scanning calorimeter can be used to perform the measurements. TPM has already been applied in Portland cements with success [23]. Many probe liquids may be used, such as water [23], cyclohexane [24] or acetonitrile [25], with the only requirement to present a solid-liquid phase transition, while the methods used to track the phase change are many [22]. In this study, water was chosen as probe liquid and the phase transition (solid-liquid) was recorded by a micro calorimeter. Advantages and drawbacks of that choice will be discussed.

The three methods described, i.e. MIP, $\mathrm{N}_{2}$ adsorption and TPM, have access only to open pores, and are applicable to different ranges of pore sizes, as represented in Fig. 1, together with the IUPAC classification of pore sizes $[22,26]$. However, not only the ranges of pore sizes are different, also the specific structural features measured vary between techniques. Thus, MIP evaluates the pore entrance size [12], whereas the gas adsorption technique allows measuring both pore size and pore entrance size, using the adsorption and desorption curves respectively $[20,27]$. TPM allows the determination of the size of the cavity of the pore during the melting cycle and the pore entrance size during the freezing cycle $[21,27]$. 
The objective of this work is to perform a critical assessment of the suitability of the different techniques described, i.e. gas sorption, mercury intrusion and TPM, for the characterization of the porosity and pore structure of apatitic CPCs obtained by hydrolysis of $\alpha$-tricalcium phosphate ( $\alpha$-TCP) [28-30]. Four cements, with a range of different porosities are compared, in order to evaluate the information that can be obtained from them, as well as the advantages and limitations of each technique.

\section{Materials and Methods}

\subsection{Materials}

$\alpha$-TCP was used for the preparation of the cement's solid phase, and was obtained by heating in a furnace (Hobersal CNR-58) in air a 2:1 molar mixture of calcium hydrogen phosphate $\left(\mathrm{CaHPO}_{4}\right.$, Sigma Aldrich) and calcium carbonate $\left(\mathrm{CaCO}_{3}\right.$, Sigma Aldrich) at $1400{ }^{\circ} \mathrm{C}$ for $15 \mathrm{~h}$ followed by quenching in air. Four cements with different microstructures and porosities were prepared, by varying the initial particle size and liquid to powder ratio, as described in a previous paper [5] (Fig. 2). To this end, the $\alpha$ TCP obtained was milled in a planetary mill (Pulverisette 6, Fritsch GmbH) using an agate bowl (10 $\mathrm{cm}$ diameter) and balls, following two different protocols in order to prepare two different granulometries: i) a coarse (C) powder, obtained by milling with 10 balls $(\mathrm{d}=30 \mathrm{~mm})$ for $15 \mathrm{~min}$ at $450 \mathrm{rpm}$; ii) a fine $(\mathrm{F})$ powder, obtained by milling in three steps: first with 10 balls $(\mathrm{d}=30 \mathrm{~mm})$ for $60 \mathrm{~min}$ at $450 \mathrm{rpm}$, followed by 40 min at $500 \mathrm{rpm}$, and a last step with 100 balls $(\mathrm{d}=10 \mathrm{~mm})$ for $60 \mathrm{~min}$ at $500 \mathrm{rpm} .2 \mathrm{wt}$ $\%$ of precipitated hydroxyapatite (Merck, US) was added as a seed in the powder.

Cements were prepared with two different liquid-to-powder $(\mathrm{L} / \mathrm{P})$ ratios of 0.35 and $0.65 \mathrm{~mL} / \mathrm{g}$ using both $\mathrm{F}$ and $\mathrm{C} \alpha-\mathrm{TCP}$ powders. The powder phase was mixed with water in a mortar for about $1 \mathrm{~min}$ and then transferred into $6 \mathrm{~mm}$ diameter $\mathrm{x} 12 \mathrm{~mm}$ 
height cylindrical Teflon moulds. The samples were allowed to set at $100 \%$ relative humidity for 7 days at $37^{\circ} \mathrm{C}$. CPCs obtained were coded as C35, C65, F35 and F65, where $\mathrm{C}$ or $\mathrm{F}$ stand for coarse or fine powder respectively, and 35 or 65 correspond to the liquid-to-powder ratio.

\subsection{Phase composition and microstructure characterization}

The hardened CPC samples were dried at $60^{\circ} \mathrm{C}$ for $24 \mathrm{~h}$, and the phase composition was assessed by X-ray diffraction (XRD) using a PAN-Alytical X'Pert powder X-Ray diffractometer. Scanning was performed in the Bragg-Brentano geometry using $\mathrm{CuK} \alpha$ radiation with the following conditions: $2 \theta$ scan step 0.016 between 20 and 70, counting time $50 \mathrm{~s}$ per step, voltage $45 \mathrm{kV}$ and intensity $40 \mathrm{~mA}$. To observe the inner microstructure of the material, the specimens were fractured and the fracture surfaces were observed using a Field Emission Scanning Electron Microscope (SEM, JEOL JSM-7001F). Prior to observation the samples were AuV-sputter coated (Emitech K950X, US).

\subsection{Sequence of analysis}

The techniques selected have been described as being highly reproducible [23,31-34], and have been stated to be precise both method and material related [35]. Therefore, the same 4 cylinders of each composition have been tested in the different techniques according to the following sequence:

CPC preparation \& setting $\rightarrow$ TPM $\rightarrow$ drying $\rightarrow \mathrm{N}_{2}$ sorption $\rightarrow$ MIP

\subsection{Total porosity}

The value of the total porosity $\left(\mathrm{P}_{\text {ТОт }}\right)$ was calculated following Eq. 1. 


$$
P_{\text {TOT }}(\%)=\left(1-\frac{\rho_{a p p}\left(\mathrm{~g} / \mathrm{cm}^{3}\right)}{\rho_{\text {skel }}\left(\mathrm{g} / \mathrm{cm}^{3}\right)}\right) \cdot 100 \quad \text { Equation } 1
$$

The apparent density $\rho_{a p p}$ was determined by Mercury Intrusion Porosimetry (Autopore IV 9500 porosimeter, Micromeritics, USA) using the envelope volume measured at 0.54 psia, and the skeletal density of the samples $\left(\rho_{\text {skel }}\right)$ was determined by Helium pycnometry (AccuPyc 1330, Micromeritics, USA) [36].

\subsection{Nitrogen Sorption}

The gas sorption experiments were performed in an ASAP 2020 (Micromeritics, USA), using $\mathrm{N}_{2}$ as the adsorbate. Four cylinders of each composition were degassed at $10 \mathrm{~mm}$ $\mathrm{Hg}$ at $90^{\circ} \mathrm{C}$ during $1 \mathrm{~h}$ followed by $2 \mathrm{~h}$ at $100{ }^{\circ} \mathrm{C}$. The adsorption and desorption isotherms were recorded. The specific surface area (SSA) for each composition was reported using the 8 points Brunauer-Emmett-Teller (BET) theory. The Barrett-JoynerHalenda $(\mathrm{BJH})$ theory was applied for the treatment of the data, to determine the pore size distribution (PSD), using the adsorption branch and the pore entrance size distribution (PESD) using the desorption branch of the curve, based on the Kelvin equation (Eq. 2).

\section{$1>1: I \mathrm{E} \quad \mathrm{t} \stackrel{\circ}{\eta}=$ Equation 2}

Where $\mathrm{P}_{\mathrm{v}}$ is the equilibrium vapor pressure, $\mathrm{P}_{\text {sat }}$ the saturation vapor pressure, $\mathrm{H}$ the mean curvature of meniscus, $\gamma$ the liquid/vapor surface tension, $V_{1}$ the liquid molar volume, $\mathrm{R}$ the ideal gas constant and $\mathrm{T}$ the temperature. Different models can be applied to convert the data in pore size distribution, one of the most common being the BarrettJoyner-Halenda (BJH) method [16], which makes use of the combined effect of capillary condensation in the inner pore volume, and physical adsorption on the pore 
walls, and assumes that pores are cylindrical. It provides the pore size distribution at the nanometer range [20].

The total porosity $\left(\mathrm{P}_{\mathrm{N} 2}\right)$ was calculated using the total volume of pores per gram $\mathrm{V}_{\mathrm{p}}$ and the skeletal density of the materials $\left(\rho_{\text {skel }}\right)$ obtained by He pycnometry, following Eq. 3:

$$
\boldsymbol{P}_{N 2}(\%)=\frac{V_{p}\left(\mathrm{~cm}^{3} / \mathrm{g}\right)}{V_{p}\left(\mathrm{~cm}^{3} / \mathrm{g}\right)+{ }^{1} / \rho_{\text {skel }}\left(\mathrm{g} / \mathrm{cm}^{3}\right)} \cdot \mathbf{1 0 0} \quad \text { Equation } 3
$$

\subsection{Mercury Intrusion Porosimetry (MIP)}

MIP experiments were performed in the same specimens previously analysed by $\mathrm{N}_{2}$ sorption, using an Autopore IV 9500 porosimeter (Micromeritics, USA), with tridistilled mercury. Four cylinders were used for each measurement. The intrusion and extrusion curves were recorded, and the PESD was obtained from the intrusion curve. The porosity $\left(\mathrm{P}_{\mathrm{MIP}}\right)$ was calculated as the integral of the curve obtained. The pressure needed to force mercury into the specimen can be converted to equivalent pore sizes, using the equation derived by Washburn (Eq. 4).

$$
P=-2 \cdot \gamma \cos \theta / r \quad \text { Equation } 4
$$

Where $\mathrm{P}$ is the pressure causing the intrusion, $\mathrm{r}$ is the radius of the cylindrical pore being intruded, $\gamma$ is the surface tension of mercury, and $\theta$ is the contact angle between the mercury and the pore wall.

\subsection{Thermoporometry (TPM)}

The TPM experiment was performed using a differential scanning calorimeter microDSC III (DSC, Setaram, France). CPC samples were saturated with distilled water 
by immersing them at 40 mbar during $24 \mathrm{~h}$. Two wet cylindrical samples $(6 \mathrm{~mm}$ diameter, $4 \mathrm{~mm}$ height) were placed in the chamber, letting a thin layer of water around the samples. The thermal cycle applied was:

- Tempering to $-20^{\circ} \mathrm{C}$ and isotherm during $15 \mathrm{~min}$;

- Heating (melting cycle) until $-0.01{ }^{\circ} \mathrm{C}$ at a rate of $0.2{ }^{\circ} \mathrm{C} / \mathrm{min}$;

- Freezing until $-20{ }^{\circ} \mathrm{C}$ at a rate of $0.2^{\circ} \mathrm{C} / \mathrm{min}$ (cooling cycle).

The initial temper to $-20{ }^{\circ} \mathrm{C}$ allowed freezing all the water in the DSC capsule. The heating step up to $-0.01{ }^{\circ} \mathrm{C}$ was slow to reduce any thermal lag and led to the melting of all ice confined in the pores but not of the bulk ice (the ice between the capsule and the sample). The bulk ice provided nucleation sites for the water confined in the samples to convert into ice during the following cooling step to prevent metastability of water [23]. The total porosity $\left(\mathrm{P}_{\mathrm{TPM}}\right)$ was determined by the total amount of water absorbed by direct weighting of the samples. The PSD and the PESD were evaluated using the heating and cooling cycles respectively, based on the Gibbs-Thompson equation that relates the depression of the freezing or melting temperature with curvature of the liquid-solid interface (Eq. 5).

$$
\begin{array}{ll}
\Delta T=T-T_{0}=-\frac{\gamma_{l s} \cdot T_{0}}{\rho . \Delta H} \frac{d A}{d V} & \text { Equation } 5
\end{array}
$$

Where $\Delta \mathrm{T}$ is the melting point depression, $\mathrm{T}_{0}$ is the bulk melting temperature, $\gamma_{\mathrm{ls}}$ is the surface tension of liquid-solid interface, $\rho$ is the density, $\Delta H$ is the specific enthalpy of melting, and $\mathrm{dA} / \mathrm{dV}$ is the curvature of the solid-liquid interface which is $1 / \mathrm{r}$ for a cylinder and $2 / \mathrm{r}$ for a sphere, where $\mathrm{r}$ is the radius of the curvature [22].

\subsection{Pore Size Distribution (PSD) and Pore Entrance Size Distribution (PESD)}

\section{Representation}


The size distribution curves were all represented using the logarithm of the differential volume of pores as a function of the pore (entrance) size diameter using a logarithmic scale to facilitate visual interpretation of the curves [37]. By using this distribution, a square of given area placed at a random position under the curve represents a constant volume [38].

\section{Results}

\subsection{Phase composition and microstructure}

According to the XRD studies, the hardened cement specimens after 7 days of reaction consisted of a single-phase calcium deficient hydroxyapatite (Data not shown). No residual $\alpha$-TCP was found, indicating that the hydrolysis reaction was complete. The morphology of the fracture surfaces of the four different compositions studied is shown in Fig. 3.

In the case of cements prepared with a low L/P (C35 and F35), a highly packed network of entangled crystals was observed. At high L/P (C65 and F65), aggregates of entangled crystals were present generating a more open structure. The fracture took place between the aggregates, revealing an irregular morphology. As expected, cements prepared from coarse particle size presented mainly plate-like crystals while fine initial particle size mostly led to the formation of needle-like crystals.

The specific surface area for each composition as measured by $\mathrm{N}_{2}$ adsorption using the BET technique is reported in Table 1. A major influence of the initial particle size was observed, the SSA increasing with decreasing initial particle size from 18.13 to 31.46 $\mathrm{m}^{2} / \mathrm{g}$ for $\mathrm{L} / \mathrm{P}=0.35 \mathrm{~mL} / \mathrm{g}$ and from 22.60 to $39.69 \mathrm{~m}^{2} / \mathrm{g}$ for $\mathrm{L} / \mathrm{P}=0.65 \mathrm{~mL} / \mathrm{g}$. Moreover, the specific surface area was higher when a higher L/P ratio was used, regardless of the initial particle size used. 


\subsection{Total porosity}

The skeletal density of the specimens $\left(\rho_{\text {skel }}\right)$ was determined by He pycnometry to be $2.74 \pm 0.02 \mathrm{~g} / \mathrm{cm}^{3}$, and was used in the calculations of total porosity afterwards. The total porosity $\left(\mathrm{P}_{\text {TOT }}\right)$, as well as the porosities measured by MIP $\left(\mathrm{P}_{\mathrm{MIP}}\right)$, nitrogen sorption $\left(\mathrm{P}_{\mathrm{N} 2}\right)$ and TPM $\left(\mathrm{P}_{\mathrm{TPM}}\right)$ are represented in Fig. 4. $\mathrm{P}_{\mathrm{TOT}}$ was larger than the porosities determined by the other techniques in all series, followed as a general rule by $\mathrm{P}_{\mathrm{MIP}}$ and $\mathrm{P}_{\mathrm{TPM}}$, the porosity determined by $\mathrm{N}_{2}$ sorption tending to provide the smallest value. In general, porosity was logically mainly influenced by the L/P used, while the powder particle size had only a minor effect.

\subsection{Mercury Intrusion Porosimetry}

The Hg intrusion and extrusion curves for the cumulative volume as a function of the pore entrance diameter obtained by MIP is shown in Fig. 5. The intruded volume was significantly higher for high L/P ratio. Moreover, the mismatch between intrusion and extrusion curves highlights the presence of a particular type of porosity consisting of large cavities connected by small openings. Hysteresis was higher when using a low L/P ratio regardless of the initial particle size used.

Two different distributions were found for the pore entrance diameter regardless of the initial particle size used. At low $\mathrm{L} / \mathrm{P}(0.35 \mathrm{~mL} / \mathrm{g})$, a unimodal distribution centred at 8 and $11 \mathrm{~nm}$ for $\mathrm{C} 35$ and F35, respectively, was recorded. At high $\mathrm{L} / \mathrm{P}(0.65 \mathrm{~mL} / \mathrm{g})$, the PESD was bimodal. For both C65 and F65, the first and second peaks were observed at $30 \mathrm{~nm}$ and $700 \mathrm{~nm}$ respectively.

\subsection{Nitrogen Sorption}

The isotherms of $\mathrm{N}_{2}$ adsorption and desorption for each sample are reported in Fig. 6. All isotherms were identified to be type $\mathrm{IIb}$, and displayed a $\mathrm{H} 3$ hysteresis loop. 
According to the literature, type IIb isotherms are typical of adsorbents having mesopores and macropores [20]. The amount of $\mathrm{N}_{2}$ adsorbed at maximum pressure was higher in the samples prepared with higher L/P ratio, while the use of a coarse initial particle size led to larger hysteresis loops, irrespective of the L/P used.

The PSD and PESD are shown also in Fig. 6. The curves of PESD, obtained from the desorption isotherm, were corrected taking into account the tensile strength effect. This correction is associated to the forced closure of the hysteresis loop that is produced around $\mathrm{p} / \mathrm{p}_{0}=0.45$. The direct application of the $\mathrm{BJH}$ model to this segment of the curve would lead to misinterpretation of the PESD, erroneously attributing it to a narrow distribution of pores centered around $4 \mathrm{~nm}$, which is actually an artefact [39]. In the case of the material prepared with coarse initial powder, C65 presented a higher volume of slightly bigger pores than C35, with pore diameters centred at 100 and $80 \mathrm{~nm}$ respectively. In contrast, the pore entrance size was bimodal for $\mathrm{C} 65$, with peaks at 10 and $70 \mathrm{~nm}$ as compared to the unimodal PESD of C35, showing a lower volume centred at $7 \mathrm{~nm}$. F35 and F65 had similar unimodal PSD and PESD at 100 and $40 \mathrm{~nm}$ respectively and displaying a higher volume when using a high $\mathrm{L} / \mathrm{P}$ ratio, F65 as compared to F35.

\subsection{Thermoporometry}

The cooling and heating cycles obtained by TPM are reported in Fig. 7. Both C35 and C65 presented a freezing exothermic peak at lower temperature than the corresponding endothermic melting peak. F35 and F65 presented a bimodal freezing exothermic profile and unimodal endothermic melting peak.

Cements prepared with coarse initial powder size, C35 and C65, presented a unimodal PSD centred at $30 \mathrm{~nm}$ and $35 \mathrm{~nm}$ respectively. A higher volume of pores was recorded 
for C65 as compared to C35. The PESD of C65 was bimodal with a peak at $80 \mathrm{~nm}$ and a shoulder at $15 \mathrm{~nm}$ while $\mathrm{C} 35$ showed two peaks at $10 \mathrm{~nm}$ and $80 \mathrm{~nm}$. The PESD volume recorded was higher for C65.

Materials prepared with fine initial particle size, F35 and F65 had very similar PSDs centred both at $30 \mathrm{~nm}$. The PESD of F65 was shifted to slightly higher values compared to F35 (35 and $20 \mathrm{~nm}$ respectively). In all cases, F65 presented a slightly higher volume compared to F35.

\section{Discussion}

\subsection{Microstructure and total porosity}

The SEM observations (Fig. 3) revealed that CPCs prepared with coarse initial particle size (C35 and $\mathrm{C} 65)$ presented plate-like crystals, while the ones prepared with fine initial particle size (F35 and F65) led to the formation of needle-like crystals, with higher SSA values (Table 1), in accordance with previous studies $[5,6]$. Also, the materials prepared with low $\mathrm{L} / \mathrm{P}$ showed a denser structure as compared to the ones prepared with high $\mathrm{L} / \mathrm{P}$. This trend was consistent with the higher total porosity measured for the cements with high L/P (Fig. 4). However, clear differences were observed between the porosity quantified using the different techniques. In fact, it has to be considered that the total porosity measured by pycnometry $\left(\mathrm{P}_{\mathrm{TOT}}\right)$ includes both open and closed pores, and covers the entire range of sizes. In contrast, the other three techniques used, i.e. MIP, $\mathrm{N}_{2}$ sorption and TPM, account only for the open pores that are accessible to a liquid (either $\mathrm{Hg}$ or water) or a gas $\left(\mathrm{N}_{2}\right)$, and cover a limited range of sizes determined by the underlying physical principles (Fig. 1). Taking this into account, a good correlation was found between the values of porosity and the size range covered by each technique, as the general trend was that $\mathrm{P}_{\mathrm{TOT}}>\mathrm{P}_{\mathrm{MIP}}>\mathrm{P}_{\mathrm{TPM}}>\mathrm{P}_{\mathrm{N} 2}$. 
Specifically, in the MIP measurement, the pores smaller than $6 \mathrm{~nm}$ were not accounted for. Thus, assuming that the samples did not contain non-interconnected pores, the comparison between $\mathrm{P}_{\mathrm{TOT}}$ and $\mathrm{P}_{\mathrm{MIP}}$ (Fig. 4) allowed calculating the porosity that can be ascribed to pores smaller than $6 \mathrm{~nm}$, obtaining the values of $9.5,2.7,5.3$ and $3.5 \%$ for C35, C65, F35 and F65 respectively. This indicates that the samples prepared with a low L/P ratio exhibited a higher amount of pores with entrance diameters smaller than 6 $\mathrm{nm}$, which can be associated to a more compact structure and smaller spaces between crystals.

\subsection{Pore structure assessed by MIP}

MIP provides information on the pore size distribution over a larger size range than TPM and N2 sorption. It has to be emphasized however that MIP measures the diameter of the pore entrance rather than the pore diameter itself. Thus, large cavities connected by smaller necks are registered as porosity having the diameter of the necks (bottle-neck effect) $[12,40]$. The high amount of $\mathrm{Hg}$ retained inside the structure after extrusion (Fig. 5, Top), especially for the samples with low L/P, is indicative of the intricate micro/nanostructure of the CPCs, with bottle-neck shaped pores.

As revealed in the SEM images, the cements studied, especially those with low L/P (C35 and F35), contained pores of different sizes, but most of them could be reached by mercury only through a long percolative chain of very small pores. Thus, all the pore volume was attributed to the small-size pores that were surrounding bigger cavities, and a unimodal pore size distribution was registered. In contrast, the samples prepared with a higher $\mathrm{L} / \mathrm{P}$ ratio (C65 and $\mathrm{F} 65$ ) not only presented a higher porosity, but also a drastically different pore structure, with a bimodal size distribution. A second peak was 
detected around $700 \mathrm{~nm}$, which in a previous study by Espanol et al. [5] was attributed to the separation between the crystal aggregates that originate from the initial $\alpha$-TCP particles of the starting powder. The situation is represented in Figure 8 that illustrates what is known as the network effect, which is different from the bottle-neck effect of individual pores mentioned previously, and must be taken into account when interpreting the pore size distribution curves obtained by MIP. Thus, rather than providing an actual distribution of pore entrance sizes, MIP gives an indication of the threshold diameter that allows mercury penetration into the pore network $[12,40]$. This network effect can explain moreover why a few large pores seen in the SEM micrographs (Fig. 3) were not reflected in the MIP measurements (Fig. 5), which registered only submicrometric pores. Although this could be interpreted as a limitation of the technique, the possibility to determine this "accessibility" diameter is in fact very relevant, since it is related to permeability and diffusion processes taking place in the material, i.e. in the release of active substances from the material in drug delivery applications $[9,41]$ or in the absorption and entrapment of biomolecules or ions from the physiological environment $[5,42]$, which in turn have an influence in the cell response [43] and in vivo performance of the materials [1,2,4].

The strong network effect present in MIP measurements was the reason why in all cases, a higher volume of pores at smaller sizes was detected by MIP as compared to other techniques. This effect was less pronounced in the CPCs prepared with high $\mathrm{L} / \mathrm{P}$ (C65 and F65), where mercury was able to intrude into some pores of the sample at smaller pressures, although still some shift between the MIP peak and the TPM or $\mathrm{N}_{2}$ sorption peaks was present at small-size pores.

\subsection{Porosity at the nanoscale: characterization by Nitrogen Sorption and TPM}


$\mathrm{N}_{2}$ sorption and TPM provided information on both pore size and pore entrance size, although limited to diameters smaller than $200-400 \mathrm{~nm}$. In this size range, according to the model proposed by Espanol et al [5], the inter-aggregate porosity would not be detected, and only the pores between individual crystals would be recorded.

Concerning $\mathrm{N}_{2}$ sorption, the hysteresis loops for all isotherms obtained (Fig. 6, Top) were of type $\mathrm{H} 3$ according to the IUPAC classification [20]. Since there was no indication of plateau at high $\mathrm{P} / \mathrm{P}_{0}$, the isotherms should not be classified as Type IV, but as Type IIb [20,44]. This kind of isotherms are the result of interparticle capillary condensation, suggesting materials composed of aggregates of particles giving rise to slit-shaped pores $[20,45]$, which copes well with the morphology of our materials as shown in Fig. 3. However, two kinds of isotherm shapes could be easily distinguished (Fig. 6, Top). The cements prepared with coarse powder (C35 and C65) exhibited a larger width of the hysteresis loop than those prepared with fine powders (F35 and F65). This narrower loop accounts for an easier desorption for the $\mathrm{F}$ samples, as the desorption branch followed a path closer to the adsorption branch, suggesting that less narrow constrictions were present in these samples, at the nanometric scale. Moreover, the more pronounced forced closure of the hysteresis loop near $\mathrm{P} / \mathrm{P}_{0}=0.45$ for the coarse cements (C35 and C65) was indicative of pore network effects, when interconnected larger pores had to empty through pores with smaller diameter that connected the larger pores to the outer surface of the sample. This was consistent with the different morphologies of the crystals in the coarse and fine samples (Fig. 3). Whereas the coarse cements consisted mostly of plate-like crystals, the fine cements contained rather acicular crystals, the latter giving rise to a more open structure. This was evidenced also by the fact that, even if in all cases pore entrance sizes were smaller than pore sizes (Fig. 6), closer PSD and PESD curves were found in the fine cements as compared to 
the coarse ones, suggesting a smaller difference between pore size and pore neck size. It is interesting to note that, even if it covered only a fraction of the porosity, $\mathrm{N}_{2}$ sorption was able to detect with more detail the differences arising from the morphology of this type of materials at the nanoscale, which were not easily derived from the MIP results.

It is interesting to note that the same general trend was found when analysing the TPM results (Fig.7), which showed distinct results in terms of PESD when comparing fine (F) and coarse (C) cements. As happened with $\mathrm{N}_{2}$ sorption (Fig. 6), the shape of the PESD curves of the F35 and F65 cements were similar, the former (F35) being slightly displaced to smaller pore diameters. In contrast, coarse cements exhibited different PESD curves, following the same trend obtained with the $\mathrm{N}_{2}$ sorption curves.

In the light of these results, comparing the MIP and $\mathrm{N}_{2}$ adsorption data, it cannot be concluded that the drying step required for $\mathrm{N}_{2}$ adsorption measurements significantly modifies the pore structure of the CPCs. No change in the microstructure was observed by SEM after drying. While it is true that the drying step has been shown to have an impact on pore structure in some cementitious materials that contain a gel-like phase, like Portland cement [44], the situation is expected to be rather different in the CPCs analysed in this work, where the drying step at $100^{\circ} \mathrm{C}$ is expected to cause only the loss of the surface-bound water in the calcium deficient hydroxyapatite obtained as the reaction product $[46,47]$.

\subsection{Comparison between the different techniques}

The PESD and PSD obtained with the different techniques are represented together in a single diagram, for comparison (Fig. 9). When analysing the PESD curves obtained by MIP, $\mathrm{N}_{2}$ sorption and TPM in the overlapping range, a shift towards lower values was observed for MIP in the samples wit low L/P ratio, C35 and F35, (refer also to Fig. 6 to 
better appreciate the shape of the $\mathrm{N}_{2}$ sorption PESD curve at a higher magnification). These results suggest that there is no disruption of the microstructure induced by the high-pressure values during MIP measurements, and that MIP is more sensitive to the network effect than the other two techniques (Fig. 8). Indeed, during $\mathrm{N}_{2}$ sorption, $\mathrm{N}_{2}$ circulates through the sample in gaseous state, and condensates in the smaller pores at lower relative pressure, followed by bigger pores at higher relative pressure. Thus, in the case of having a big cavity surrounded by small pores (Fig. 8, left), this process would not suffer from a network effect as in the case of MIP, since the gas would condensate in the small pores first and in the big cavity later, registering a bimodal pore size distribution. In the case of TPM, the measurement is based on the freezing/melting of a confined liquid, and is performed in wet samples. Therefore, also in this case the technique is expected to be less sensitive to the network effect.

According to MIP and N2 sorption, for a given L/P ratio the pore entrance size was smaller for coarse than for fine cements (Fig. 9, left column), which can be ascribed to the different morphologies of the pores created: plate-like or needle-like crystals. This highlights the relevance of crystal morphology, and not only crystal size, on pore size. Thus, it is interesting to note that samples produced with fine initial particle size (F35 and F65) did have a higher SSA, which did not result in a smaller pore entrance size than their coarse counterparts, but rather they had larger pore entrance sizes, due to the more open spaces between acicular crystals. This trend was not observed in the TPM measurements, which showed discordant results particularly for the coarse cements, where larger pore entrance sizes were recorded. In contrast, when considering the PSD (Fig. 9, right column), in general TPM recorded smaller pore sizes as compared to $\mathrm{N}_{2}$ sorption, except for C35 cement. However, these results, that might appear contradictory, must be interpreted with caution. Different factors must be considered. 
On one hand, some studies have shown that the BJH theory tends to underestimate pore sizes [48]. On the other hand, it cannot be ruled out that some bias could be introduced by the interaction between the probe liquid used in TPM, in this case water, and the material, that could lead to a shift in the freezing point, and the consequent miscalculation of the pore size. Indeed, it is known that the presence of ions in solution, for instance calcium, produces a shift in the freezing point to lower temperature compared to pure water, at equal confinement. The use of other probe liquids such as cyclohexane or decane as non-reactive solvents and the tracking of a solid-solid phase transition could allow evaluating a wider range of pores, with a higher sensitivity of the experiment $[27,49]$.

\subsection{Methodological considerations}

Finally, the preparation protocols and the risk of sample damage should be taken into consideration. $\mathrm{N}_{2}$ sorption and TPM techniques include a soft preparation step of the sample, consisting in degassing during $24 \mathrm{~h}$ or water filling at $40 \mathrm{mbar}(0.004 \mathrm{MPa})$ during $24 \mathrm{~h}$ respectively, which can be assumed to provoke limited or no damage to the samples. It is important to remark that TPM is one of the few available methods to characterize wet samples. During measurement, the $\mathrm{N}_{2}$ sorption is non-destructive, considering that the maximum pressure applied is $0.101 \mathrm{MPa}$. During TPM measurements, the stress applied by the freezing of water and its associated volume augmentation inside the voids of the CPC is not easily evaluable. On the other hand, high pressures are applied to the samples during MIP measurements to force $\mathrm{Hg}$ penetration into the smallest pores, in this experiment $6 \mathrm{~nm}$, in other cases down to $3 \mathrm{~nm}$ pores. Although it has been hypothesized that this high isostatic pressure, representing up to $414 \mathrm{MPa}$ [10] might lead to sample cracking and to either penetration of mercury into previously non-interconnected volumes of the sample and/or to partial destruction 
of the sample's microstructure [50], no damage was observed in the samples analysed in this study.

The results presented allowed exploring the potential of the different techniques for the characterization of specific features of the pore structure of CPCs. The data were compared with SEM micrographs as a qualitative control, since the complexity of the microstructure made it difficult to extract quantitative information from the twodimensional SEM images. In this respect, it is expected that recent advances in highresolution tomography will allow obtaining reliable quantitative information on pore structure and pore size distribution, even at the nanoscale, in the near future. This indeed will yield new insights in the characterization of the pore structure of this kind of materials, and will provide a good quantitative control, against which the reported techniques will have to be validated.

\section{Conclusions}

CPCs intrinsic porosity covers a wide range of pore sizes, with intricate microstructures, and its characterization is a challenging task. The three techniques analysed have different advantages and limitations. MIP provides the unique benefit of covering a wide range of pore entrance sizes. As a counterpart, it is a destructive technique. Moreover, the outcome of this technique must be interpreted with caution, as it is strongly affected by the network effect. This, rather than being a limitation, can be understood as a very useful source of information, as it provides insights into the real accessibility of the pore network by external elements, be it cells, bacteria, drugs or nutrients for instance. $\mathrm{N}_{2}$ sorption and TPM are non-destructive techniques, and although covering a limited size range, were complementary to the MIP and allowed to 
gain new insights in the pore size morphology related to the crystal shape at the nanoscale, recording both PSD and PESD in a single experiment. The comparison between these techniques showed that for low L/P ratios the pore entrance size detected by MIP was shifted to smaller values, due to the network effect. PSD measured by TPM showed also a shift towards smaller values compared to $\mathrm{N}_{2}$ sorption, the reason of which should be further explored.

\section{Acknowledgements}

Authors acknowledge the Spanish Government for financial support through Project MAT2012-38438-C03-01, co-funded by the EU through European Regional Development Funds, and Ramon y Cajal fellowship of CC. Support for the research of MPG was received through the "ICREA Academia" Award for excellence in research, funded by the Generalitat de Catalunya. The authors acknowledge technical support by T. Trifonov in SEM imaging. 


\section{References}

[1] M.C. Von Doernberg, B. Von Rechenberg, M. Bohner, S. Grünenfelder, G.H. Van Lenthe, R. Müller, B. Gasser, R. Mathys, G. Baroud, J. Auer, In vivo behavior of calcium phosphate scaffolds with four different pore sizes, Biomaterials 27 (2006) 5186-98.

[2] J. Zhang, X. Luo, D. Barbieri, A.M.C. Barradas, J.D. de Bruijn, C.A. Van Blitterswij, H. Yuan, The size of surface microstructures as an osteogenic factor in calcium phosphate ceramics, Acta Biomater. 10 (2014) 3254-63.

[3] M.P. Ginebra, C. Canal, M. Espanol, D. Pastorino, E.B. Montufar, Calcium phosphate cements as drug delivery materials, Adv. Drug Deliv. Rev. 64 (2012) 1090110 .

[4] P. Wang, L. Zhao, J. Liu, M.D. Weir, X. Zhou, H.H.K. Xu, Bone tissue engineering via nanostructured calcium phosphate biomaterials and stem cells, Bone Research 2 (2014) 14017.

[5] M. Espanol, R.A. Perez, E.B. Montufar, C. Marichal, A. Sacco, M.P. Ginebra, Intrinsic porosity of calcium phosphate cements and its significance for drug delivery and tissue engineering applications, Acta Biomater. 5 (2009) 2752-62.

[6] M.P. Ginebra, F.C.M. Driessens, J.A. Planell, Effect of the particle size on the micro and nanostructural features of a calcium phosphate cement: A kinetic analysis, Biomaterials 25 (2004) 3453-62.

[7] M.P. Ginebra, M. Espanol, E.B. Montufar, R.A. Perez, G. Mestres, New processing approaches in calcium phosphate cements and their applications in regenerative medicine, Acta Biomater. 6 (2010) 2863-73.

[8] M.P. Ginebra, T. Traykova, J.A. Planell, Calcium phosphate cements: Competitive drug carriers for the musculoskeletal system? Biomaterials 27 (2006) 2171-7.

[9] D. Pastorino, C. Canal, M.P. Ginebra, Drug delivery from injectable calcium phosphate foams by tailoring the macroporosity-drug interaction, Acta Biomater. 12 (2015) 250-59.

[10] H. Giesche, Mercury Porosimetry: A General (Practical) Overview, Part. Part. Syst. Charact. 23 (2006) 9-19.

[11] E.W. Washburn, Note on a Method of Determining the Distribution of Pore Sizes in a Porous Material, Proc. Natl. Acad. Sci. U S A 7 (1921) 115-6.

[12] S. Diamond, Mercury porosimetry An inappropriate method for the measurement of pore size distributions in cement-based materials, Cem. Concr. Res. 30 (2000) 1517-25. 
[13] S. Chatterji, A discussion of the paper "Mercury porosimetry — an inappropriate method for the measurement of pore size distributions in cement-based materials" by S . Diamond. Mercury 31 (2001) 1657-8.

[14] C. Galle, Reply to the discussion by S . Diamond of the paper "Effect of drying on cement-based materials pore structure as identified by mercury intrusion porosimetry $\square$ : a comparative study between oven, vacuum and freeze-drying", Cem. Concr. Res. 33 (2003) 171-2.

[15] F. Moro, H. Böhni, Ink-bottle effect in mercury intrusion porosimetry of cement-based materials, J. Colloid Interface Sci. 246 (2002) 135-49.

[16] J. Schnieders, U. Gbureck, E. Vorndran, M. Schossig, T. Kissel, The effect of porosity on drug release kinetics from vancomycin microsphere/calcium phosphate cement composites, J. Biomed. Mater. Res. - Part B Appl. Biomater. 99 B (2011) 3918 .

[17] M.H. Alkhraisat, C. Rueda, J. Cabrejos-Azama, J. Lucas-Aparicio, F.T. Mariño, J. Torres García-Denche, L.B Jerez, U. Gbureck, E.L. Cabarcos, Loading and release of doxycycline hyclate from strontium-substituted calcium phosphate cement, Acta Biomater. 6 (2010) 1522-8.

[18] J.J. Thomas, H.M. Jennings, A.J. Allen, The Surface Area of Hardened Cement Paste as Measured by Various Techniques, Concr. Sc. Eng. 1 (1999) 45-64.

[19] G. Fagerlund, Determination of specific surface by the BET method, Mat. 22 (1973) 233-45.

[20] J. Rouquerol, F. Rouquerol, K.S.W. Sing, P. Llewellyn, G. Maurin, Adsorption by Powders and Porous Solids: Principles, Methodology and Applications, second ed., Academic Press, Waltham 2014

[21] M. Brun, A. Lallemand, J.F. Quinson, C. Eyraud, A new method for the simultaneous determination of the size and shape of pores: the thermoporometry, Thermochim. Acta 21 (1977) 59-88.

[22] J. Riikonen, J. Salonen, V.P. Lehto, Utilising thermoporometry to obtain new insights into nanostructured materials, J. Therm. Anal. Calorim. 105 (2010) 811-21.

[23] M. Landry, Thermoporometry by differential scanning calorimetry: experimental considerations and applications, Thermochim. Acta 433 (2005) 27-50.

[24] M. Baba, Calibration of cyclohexane solid-solid phase transition thermoporosimetry and application to the study of crosslinking of elastomers upon aging, J. Non Cryst. Solids 315 (2003) 228-38.

[25] M. Wulff, Pore size determination by thermoporometry using acetonitrile, Thermochim. Acta 419 (2004) 291-4. 
[26] K.H. Aligizaki, Pore structure of cement-based materials, Taylor \& Francis, London, 2006.

[27] Z. Sun, G. Scherer, Cement and Concrete Research Pore size and shape in mortar by thermoporometry, Cem. Concr. Res. 40 (2010) 740-51.

[28] Y. Li, X. Zhang, K. de Groot, Hydrolysis and phase transition of alphatricalcium phosphate, Biomaterials 18 (1997) 737-41.

[29] M. Espanol, J. Portillo, J.M. Manero, M.P. Ginebra, Investigation of the hydroxyapatite obtained as hydrolysis product of $\alpha$-tricalcium phosphate by transmission electron microscopy, Cryst. Eng. Comm. 12 (2010) 3318.

[30] M.P. Ginebra, E. Fernandez, E.A.P. De Maeyer, R.M.H. Verbeeck, M.G. Boltong, J. Ginebra, F.C. Driessens, J.A. Planell, Setting Reaction and Hardening of an Apatitic Calcium Phosphate Cement, J. Dent. Res. 76 (1997) 905-12.

[31] R.A. Siegel, Characterization of porous solids II, J Control Release 23 (1993) $183-4$.

[32] Ö.Z.Cebeci, Mercury intrusion porosimetry theory and its application to airentrained cement pastes and mortars, Iowa State University (1977) 1-85.

[33] M.F. De Lange, T.J.H. Vlugt, J. Gascon, F. Kapteijn, Adsorptive characterization of porous solids: Error analysis guides the way, Microporous Mesoporous Mater 200 (2014) 199-215.

[34] M. Sliwinska-Bartkowiak, J. Gras, R. Sikorski, R. Radhakrishnan, L. Gelb, K.E. Gubbins, Phase transitions in pores: experimental and simulation studies of melting and freezing, Langmuir 15 (1999) 6060-9.

[35] F. Rodriguez-Reinoso, B. McEnaney, J. Rouquerol, K. Unger, Characterization of Porous Solids VI, Elsevier, Amsterdam, 2002.

[36] A. Almirall, G. Larrecq, J.A. Delgado, S. Martínez, J.A. Planell, M.P. Ginebra. Fabrication of low temperature macroporous hydroxyapatite scaffolds by foaming and hydrolysis of an $\alpha$-TCP paste, Biomaterials 25 (2004) 3671-80.

[37] P.PA. Webb, C. Orr, Analytical methods in fine particle technology, Micromeritic Instrument Corporation, Norcross, 1997.

[38] K. Meyer, P. Klobes, Comparison between different presentations of pore size distribution in porous materials, Fresenius J. Anal. Chem. 363 (1999) 174-8.

[39] J.C. Groen, A.A. Louk, L.A.A. Peffer, J. Perez-Ramirez, Pore size determination in modified micro- and mesoporous materials. Pitfalls and limitations in gas adsorption data analysis, Microporous Mesoporous Mater. 60 (2003) 1-17.

[40] C.A. León y Leon, New perspectives in mercury porosimetry, Adv. Colloid Interface Sci. 76-77 (1998) 341-72. 
[41] C. Canal, D. Pastorino, G. Mestres, P. Schuler, M.P. Ginebra, Relevance of microstructure for the early antibiotic release of fresh and pre-set calcium phosphate cements. Acta Biomater. 9 (2013) 8403-8412.

[42] M. Espanol, I. Casals, S. Lamtahri, M.T. Valderas, M.P.Ginebra, Assessment of protein entrapment in hydroxyapatite scaffolds by size exclusion chromatography. Biointerphases 7: 37 (2012), DOI 10.1007/s13758-012-0037-7

[43] E. Engel, S. Del Valle, C. Aparicio, G. Altankov, L. Asin, J.A Planell, M.P Ginebra. Discerning the role of topography and ion exchange in cell response of bioactive tissue engineering scaffolds. Tissue Engineering A (2008), 14(8), 1341-1351.

[44] A. Korpa, R. Trettin, The influence of different drying methods on cement paste microstructures as reflected by gas adsorption: Comparing between freeze-drying (Fdrying), D-drying, P-drying and oven-drying methods, Cem. Concr. Res. 36 (2006) 63449.

[45] K.S.W. Sing, Reporting physisorption data for gas/solid systems with special reference to the determination of surface area and porosity (Recommendations 1984), Pure Appl. Chem. 57 (1985) 603-19.

[46] G.Mestres, C. Le Van, M.P. Ginebra. Silicon-stabilized $\alpha$-tricalcium phosphate and its use in a calcium phosphate cement: characterization and cell response, Acta Biomater. 8 (2012) 1169-79.

[47] J.C. Elliott. Structure and chemistry of the apatites and other calcium orthophosphates. Amsterdam: Elsevier; 1994

[48] G.S. Armatas, The possible use of $\Gamma$-functions for the determination of microporosity-mesoporosity and the pore size in materials with ordered (MCM) and quasi-ordered pore structure, Microporous Mesoporous Mater. 67 (2004) 167-74.

[49] R. Mu, V. Malhotra, Effects of surface and physical confinement on the phase transitions of cyclohexane in porous silica, Phys. Rev. B 44 (1991) 4296-303.

[50] M.A.I. LaskarRakesh, B. Bhattacharjee, Some aspects of evaluation of concrete through mercury intrusion porosimetry, Cem. Concr. Res. 27 (1997) 93-105. 


\section{Figure Captions}

Figure 1. Range of pore sizes potentially measurable by different techniques of applicability for calcium phosphate cements. Pore size nomenclature according to IUPAC.

Figure 2. Effect of the particle size and L/P ratio on the morphology of CPCs, adapted from [3].

Figure 3. Scanning Electron Micrographs of fracture cross-sections of C35, C65, F35 and F65 at low magnification (left) and high magnification (right). Top insert shows high-magnification micrograph of plate-like crystals corresponding to C CPCs. Bottom insert shows high-magnification micrograph of needle-like crystals of F CPCs.

Figure 4. Total porosity and porosity evaluated by three different techniques: MIP, TPM and $\mathrm{N}_{2}$ sorption of four different CPCs.

Figure 5. MIP Intrusion/Extrusion curves (Top) and Pore Entrance Size Distributions (Bottom) for the cements prepared with coarse initial particle size (C35 and $\mathrm{C} 65$, left) and fine initial particle size (F35 and F65, right).

Figure 6. $\mathrm{N}_{2}$ Adsorption/Desorption Isotherms (Top) and Pore Size Distributions (PSD) and Pore Entrance Size Distribution (PESD) obtained applying the BJH theory to the adsorption and desorption branch respectively (Bottom) for materials prepared with coarse initial particle size (C35 and C65, left) and fine initial particle size (F35 and F65, right).

Figure 7. TPM Solidification/Melting curves (Top) and Pore Size Distributions (PSD) and Pore Entrance Size Distribution (PESD) obtained from the melting and freezing 
curves respectively (Bottom) for cements prepared with coarse initial particle size (C35 and $\mathrm{C} 65$, left) and fine initial particle size (F35 and F65, right).

Figure 8. Schematic representation of the network effect and its influence on pore entrance size distribution recorded by mercury intrusion porosimetry (MIP). On the left, a material with large (3) and medium-sized (2) pores embedded in a network of small (1) pores, and its corresponding pore entrance size distribution MIP diagram. Mercury is able to enter the large and medium-size pores only when the pressure overcomes the threshold allowing to enter the pore network connecting the material with the exterior (Blue). On the right, a material with large (3) and small (1) pores embedded in a network of medium-sized (2) pores, and its corresponding pore entrance size distribution MIP diagram. When pressure is high enough to enter the medium-sized pores (2) it can also enter the large pores (3), (Blue). To enter the small pores (1) pressure has to increase to higher values (Red).

Figure 9. Pore entrance size distribution, PESD (left) and Pore size distribution, PSD (right) recorded using different techniques for the four different cements. 
Table 1: Specific Surface Area (SSA) as evaluated by $\mathrm{N}_{2}$ adsorption for C35, C65, F35 and F65.

\begin{tabular}{|c|c|}
\hline Composition & SSA $\left(\mathbf{m}^{2} / \mathbf{g}\right)$ \\
\hline C35 & $18.1 \pm 0.2$ \\
\hline C65 & $22.6 \pm 0.2$ \\
\hline F35 & $31.5 \pm 0.3$ \\
\hline F65 & $39.7 \pm 0.4$ \\
\hline
\end{tabular}




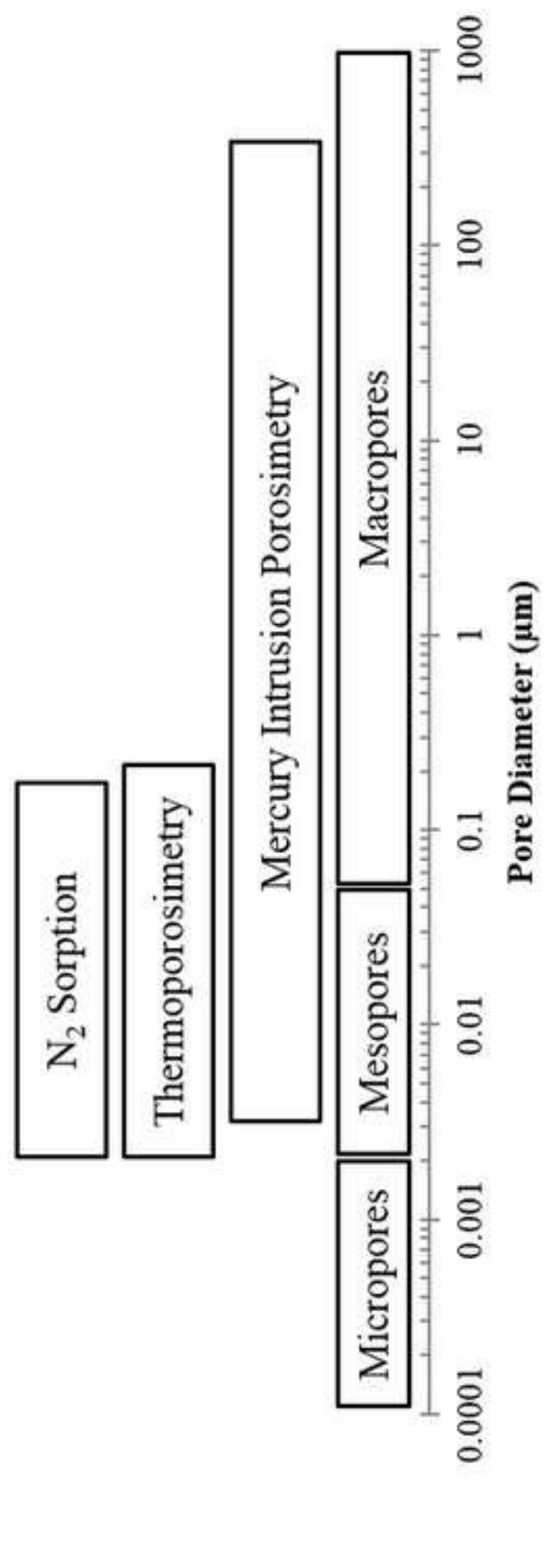



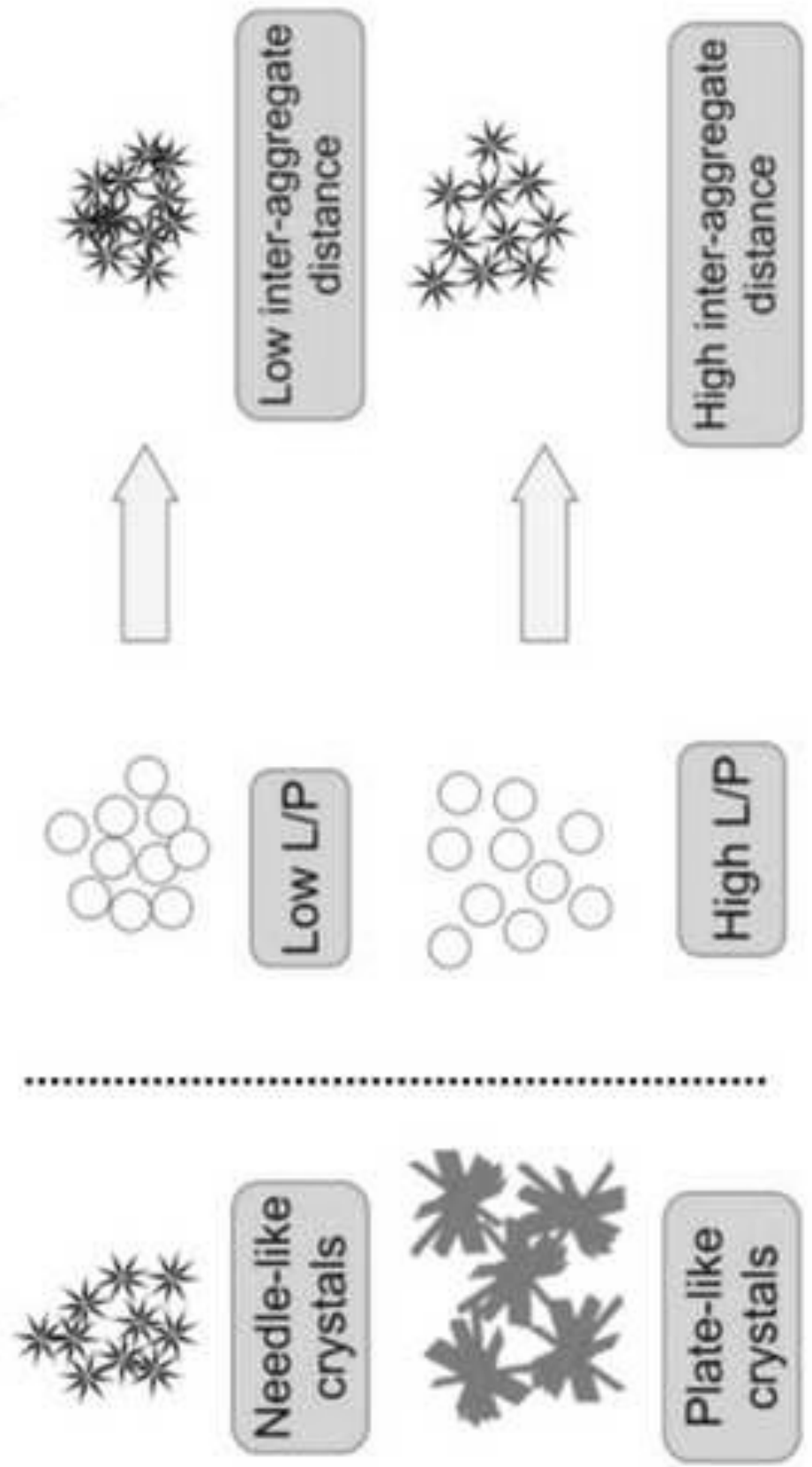

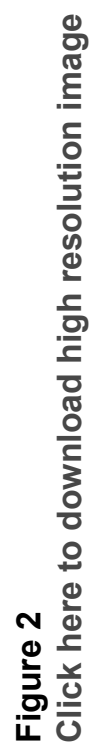
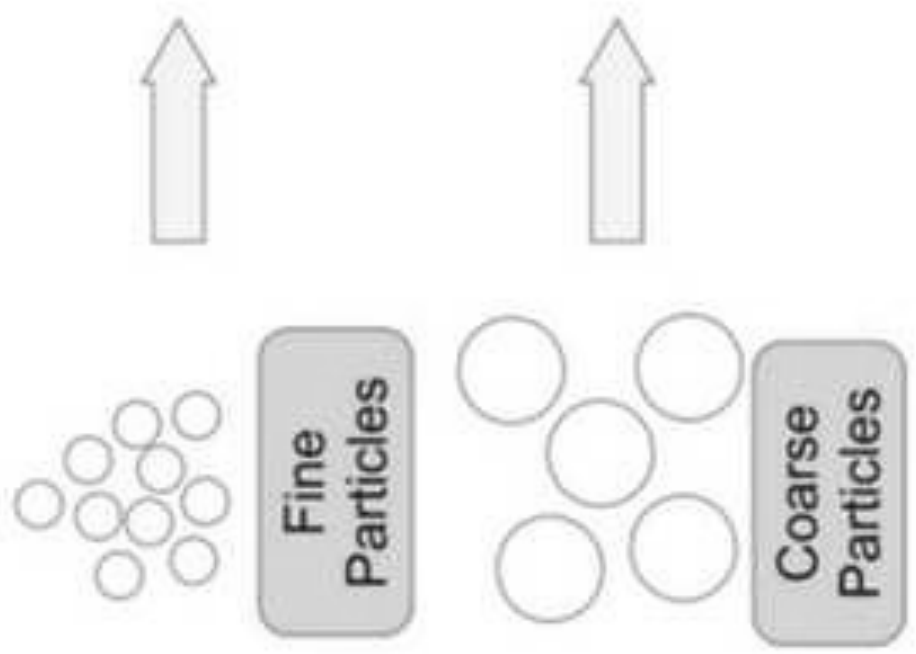


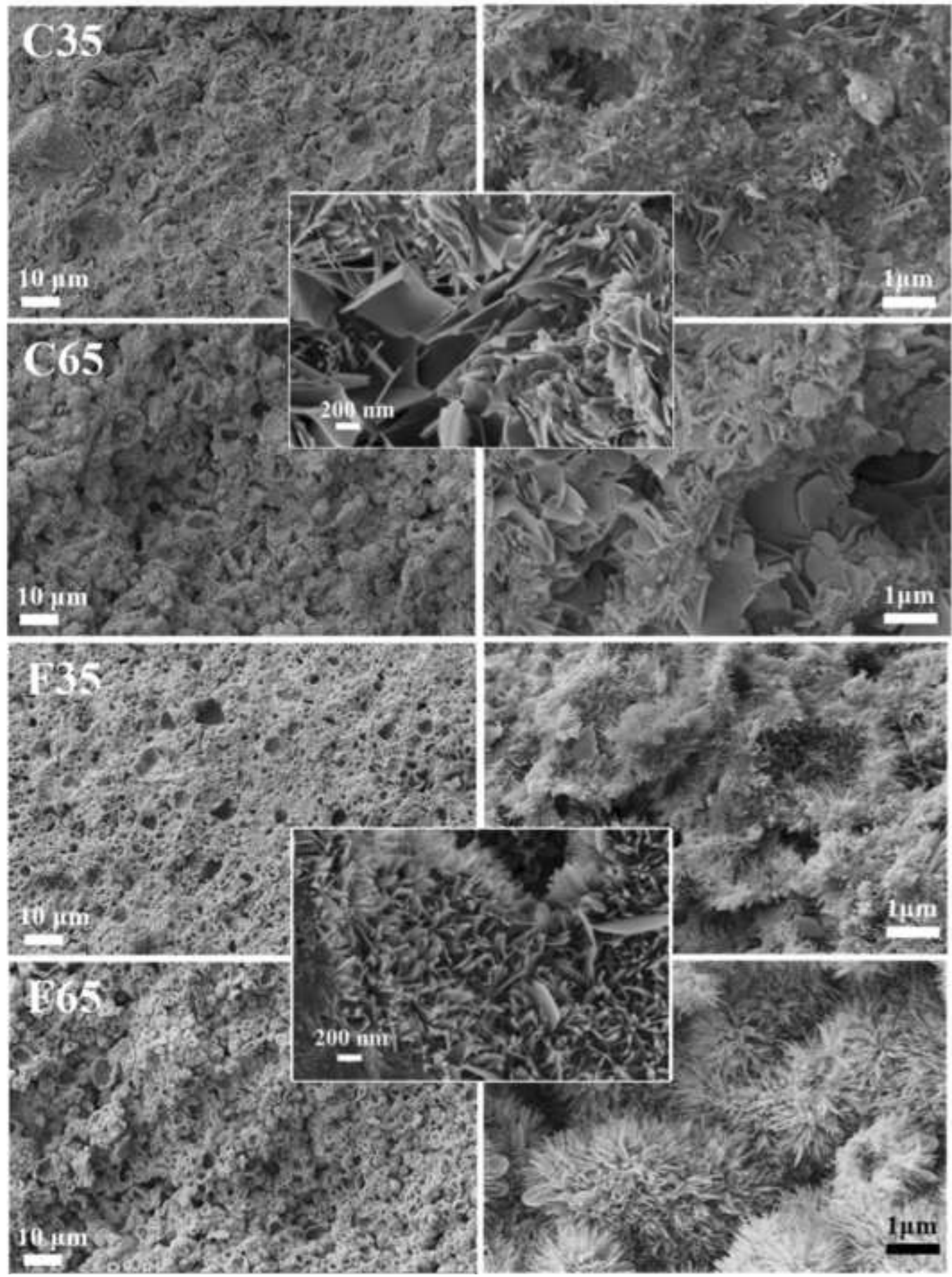




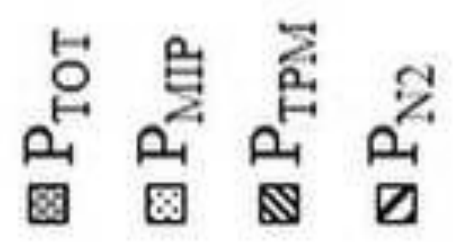

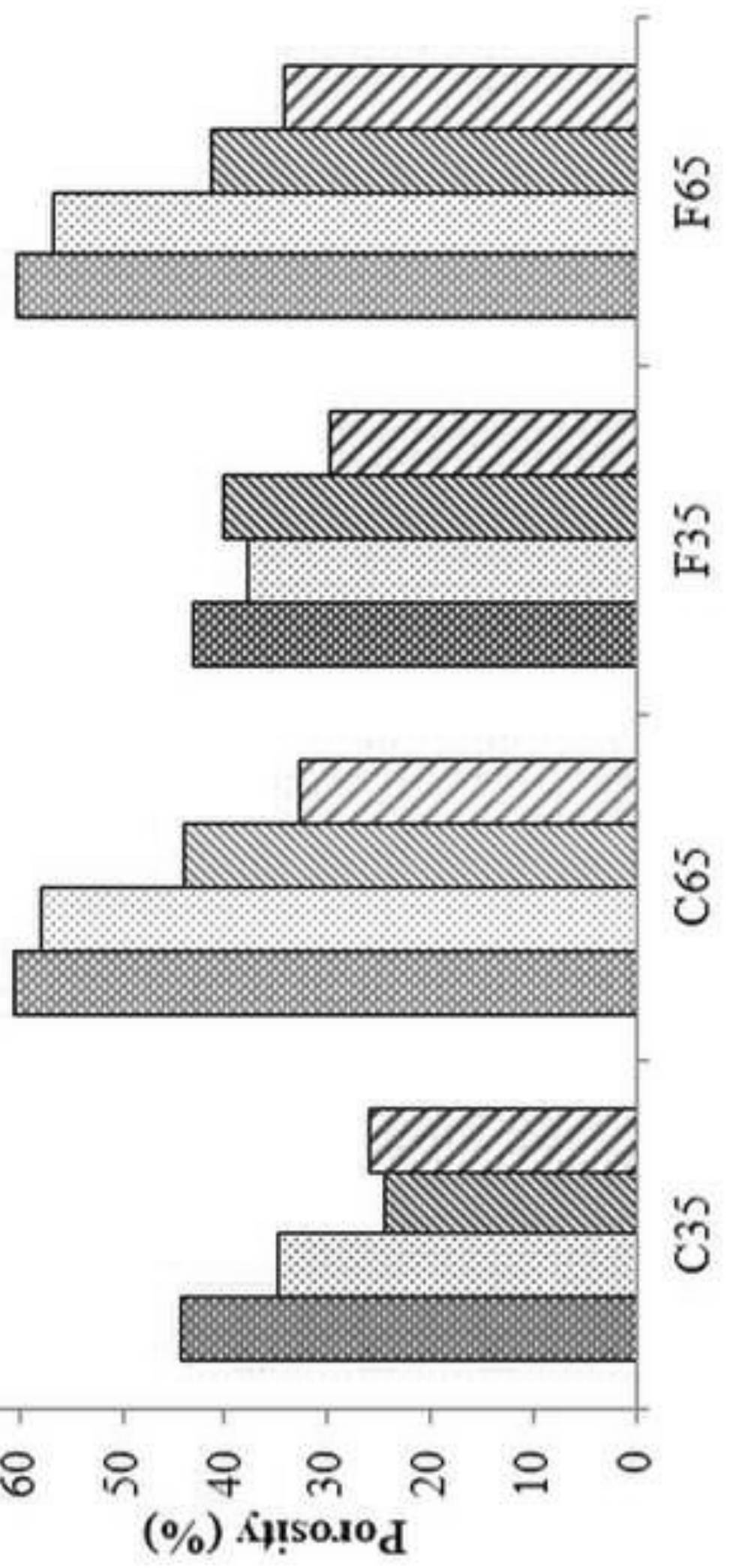




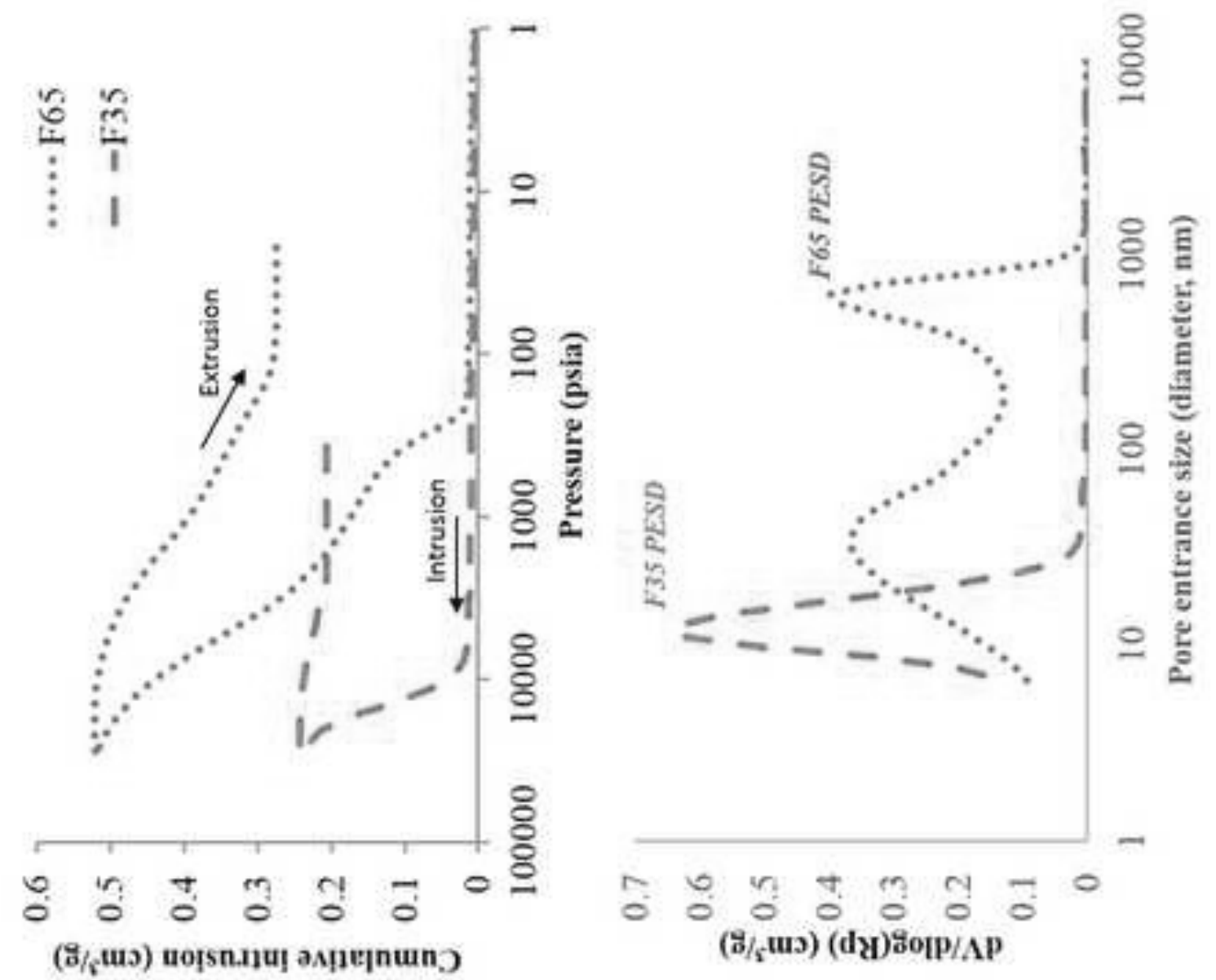

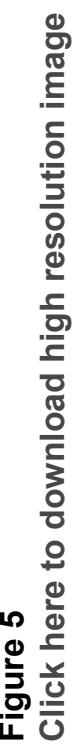

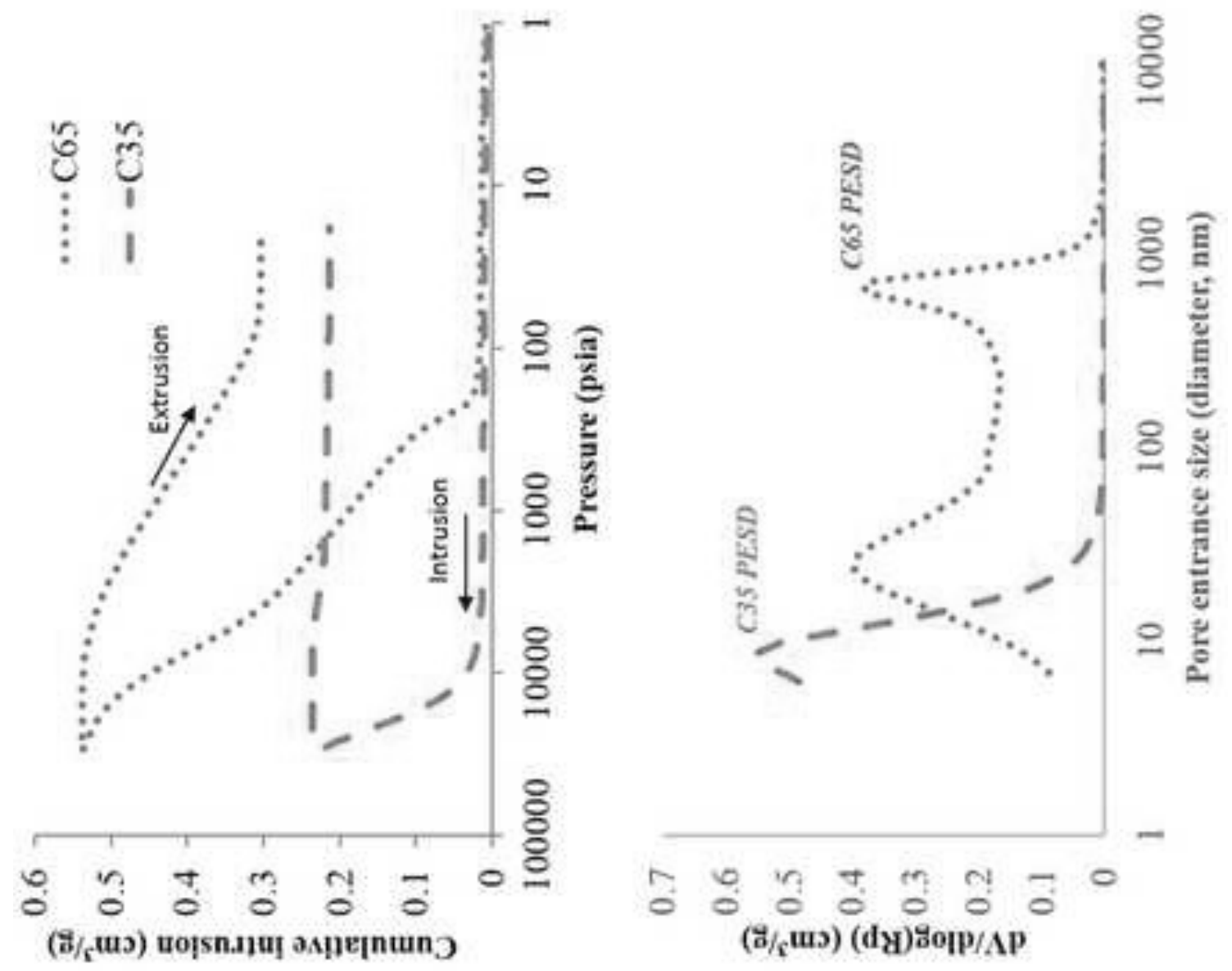



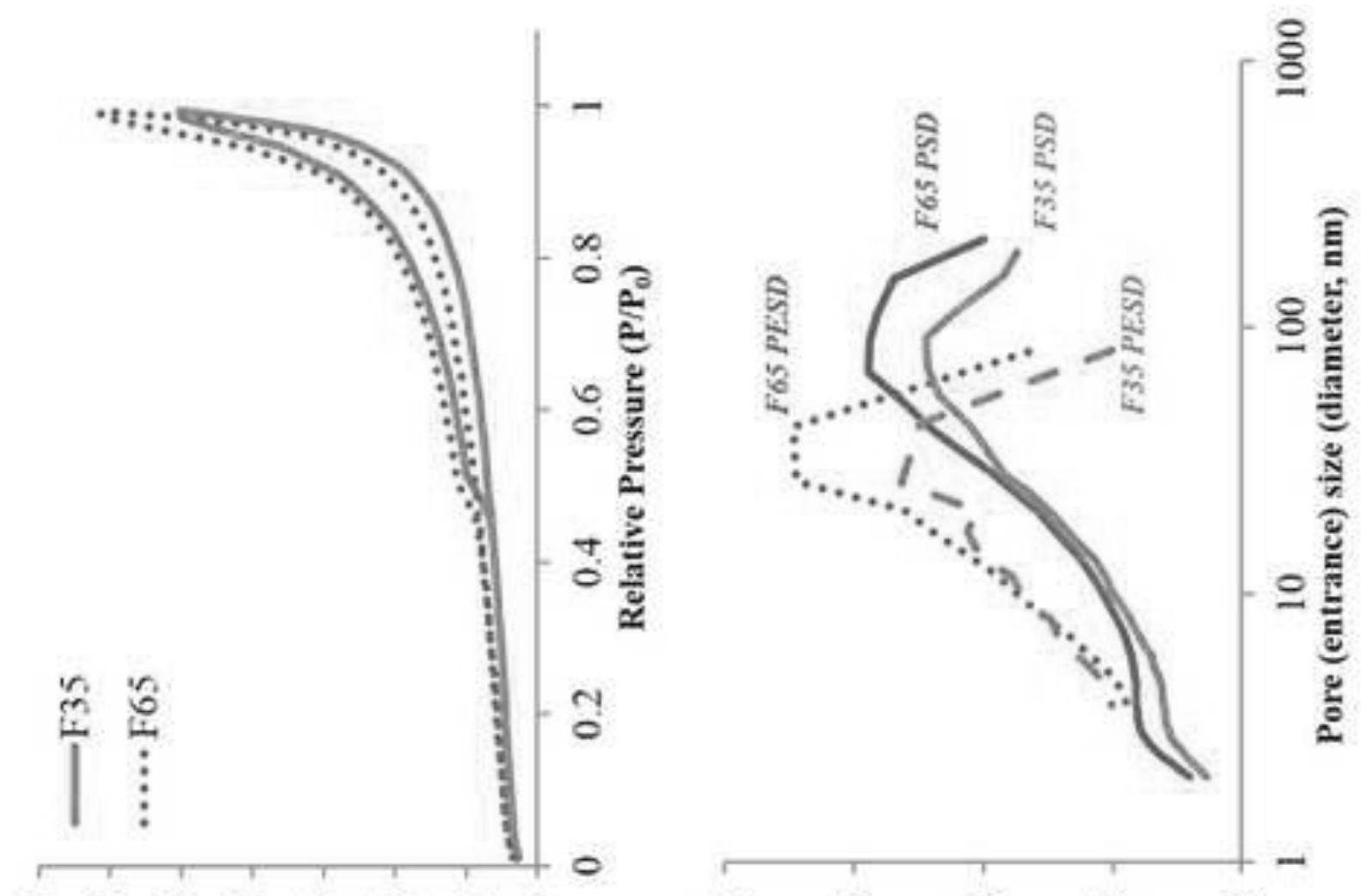

응요 응 용

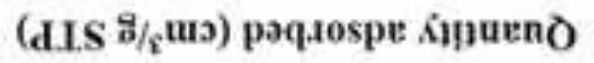

용 의 응

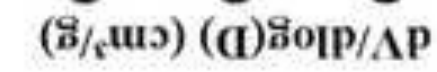
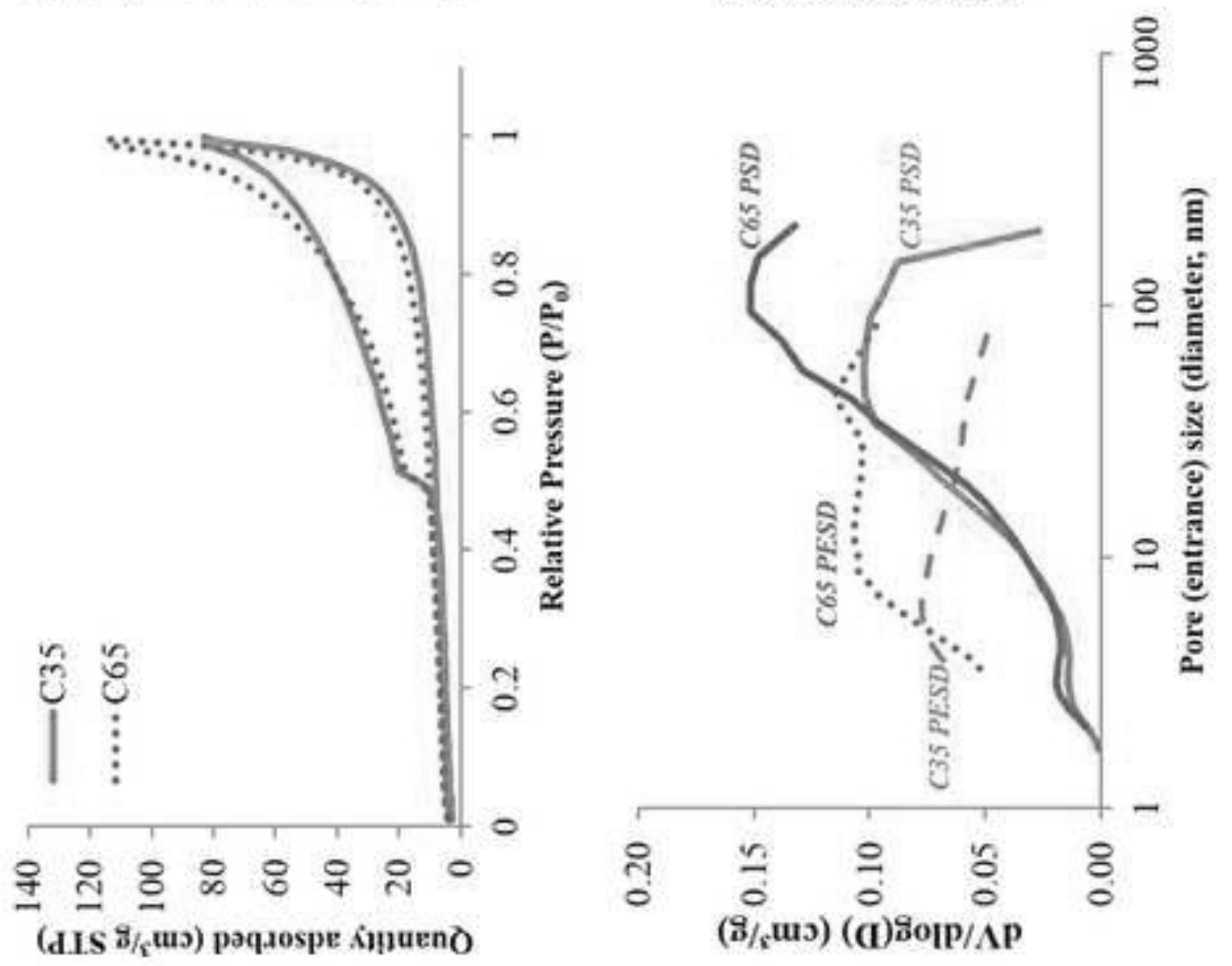


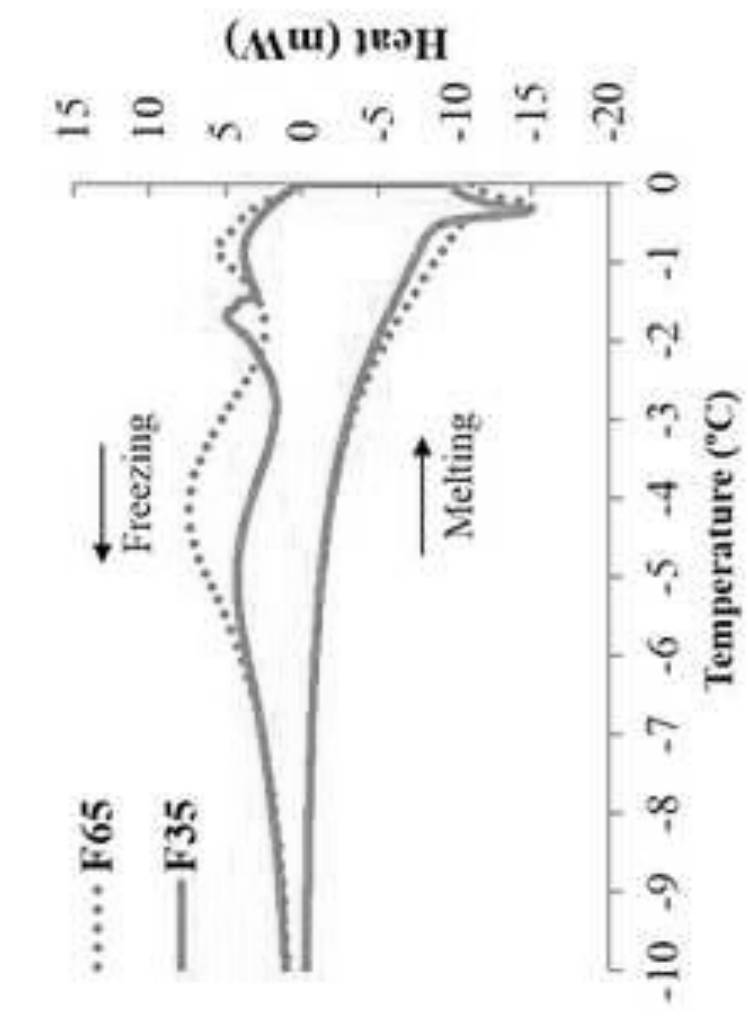

$$
\begin{aligned}
& \text { (Мu) )ะว } \\
& n \varrho n \circ m \div \frac{n}{1}
\end{aligned}
$$

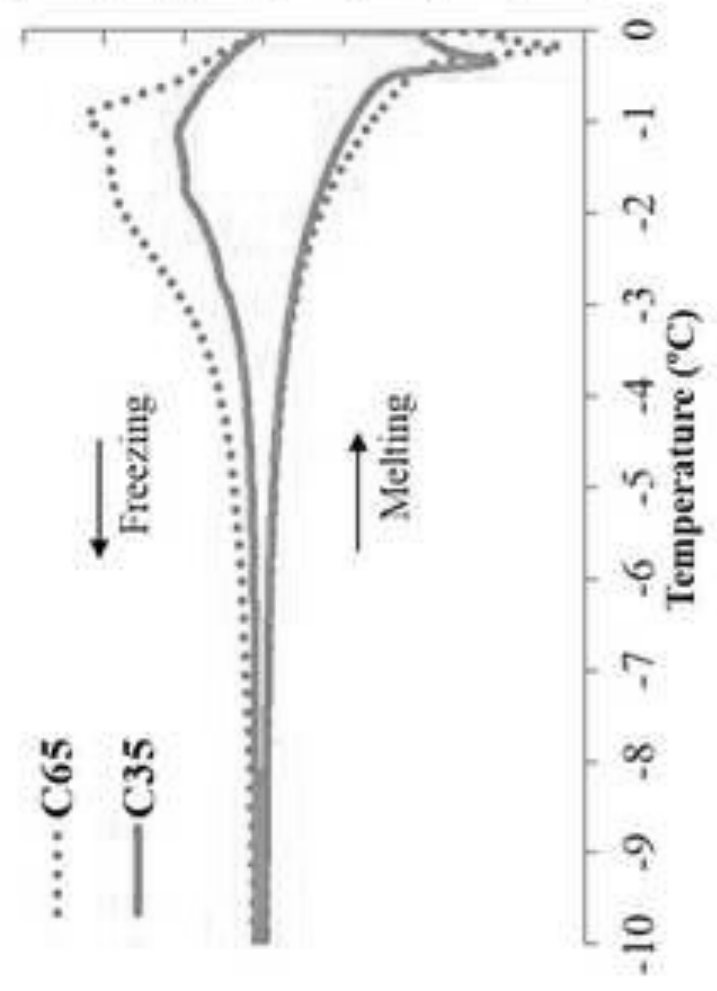

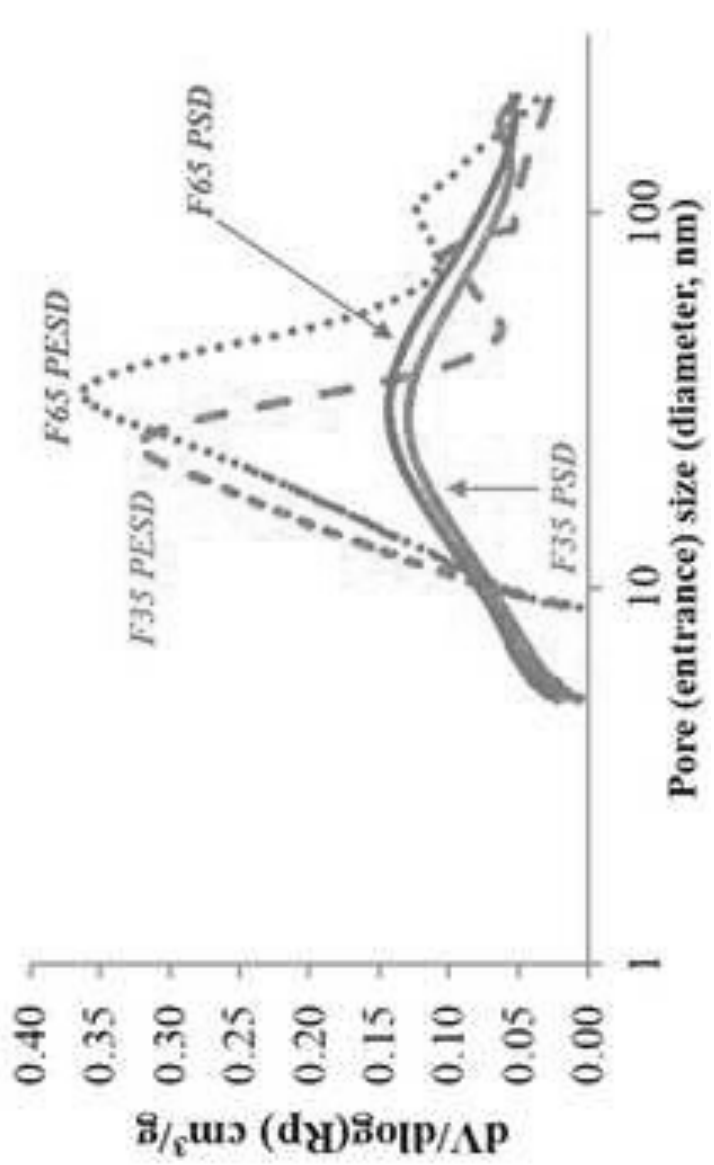

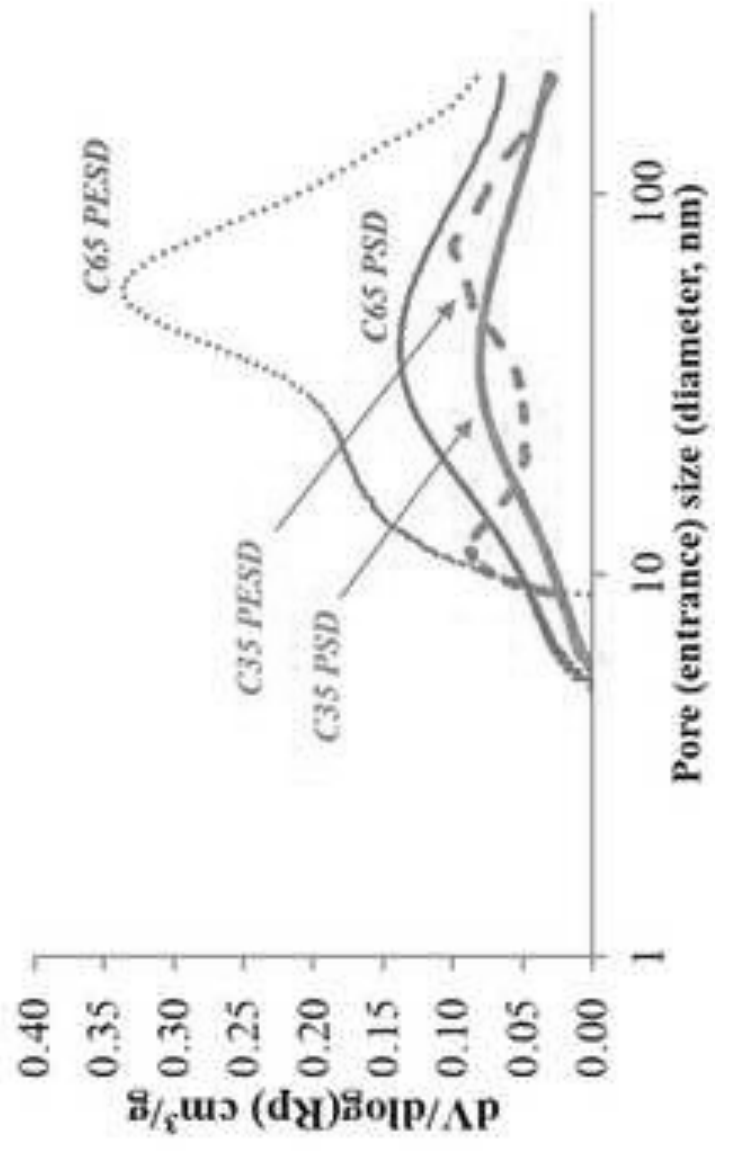



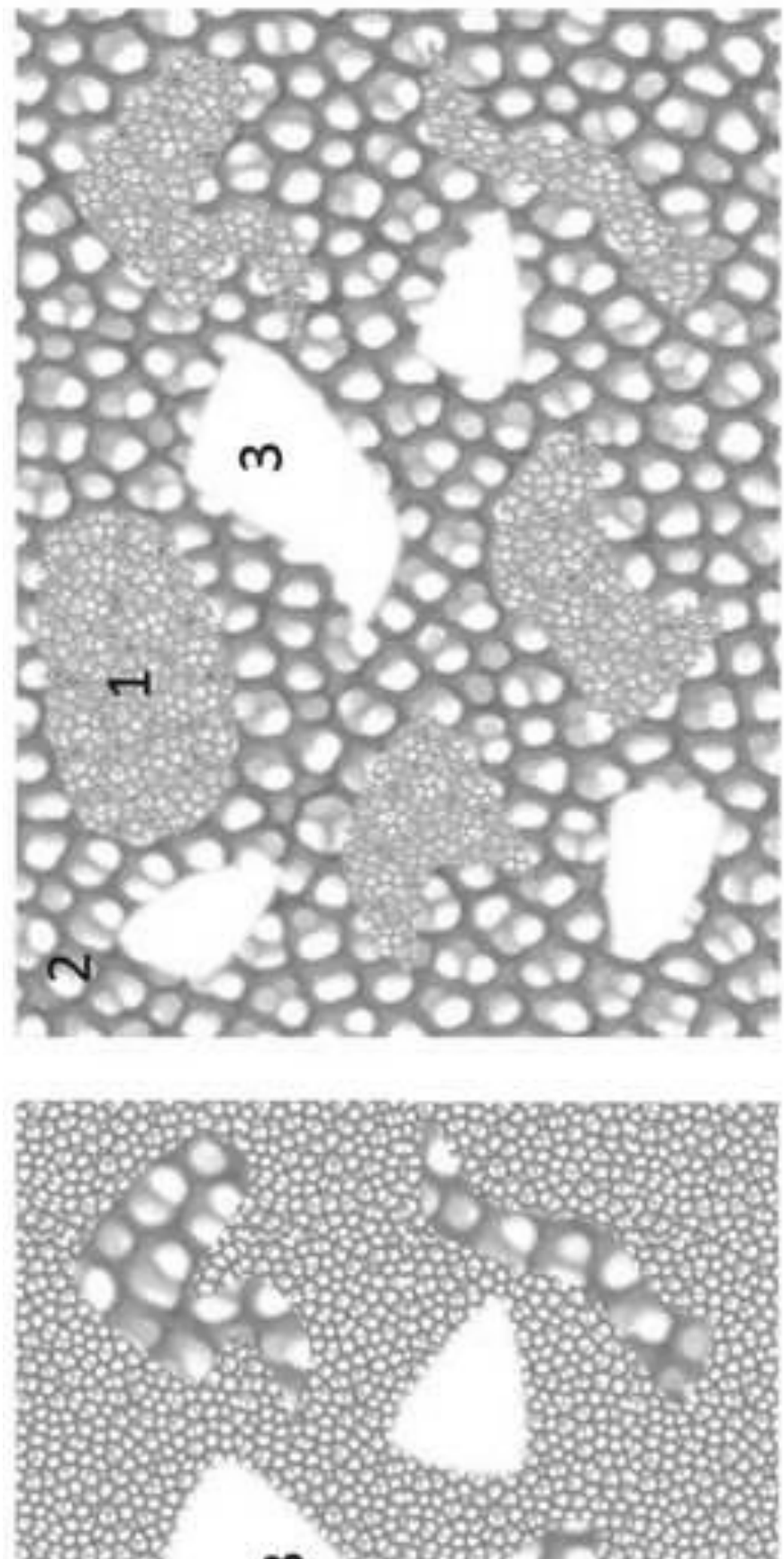

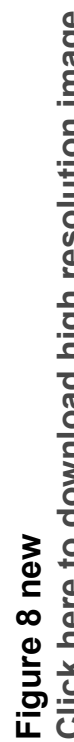

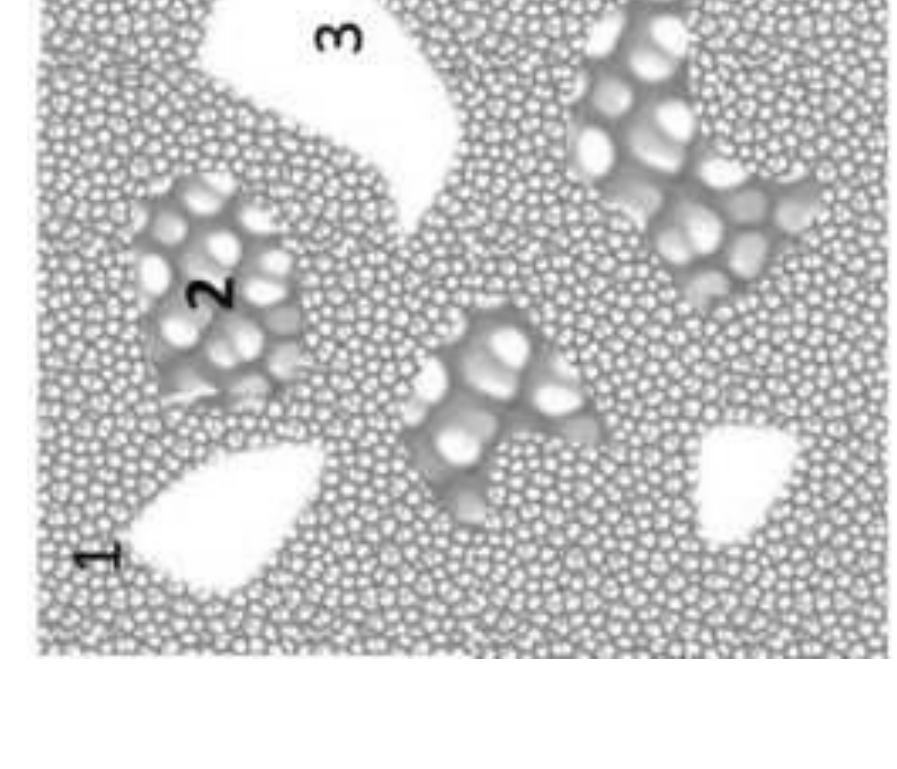

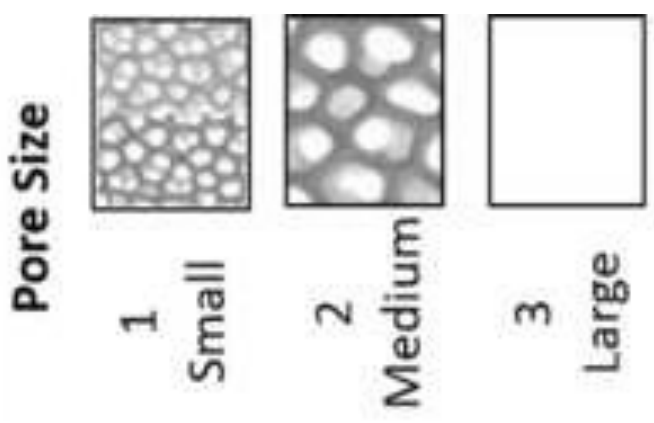
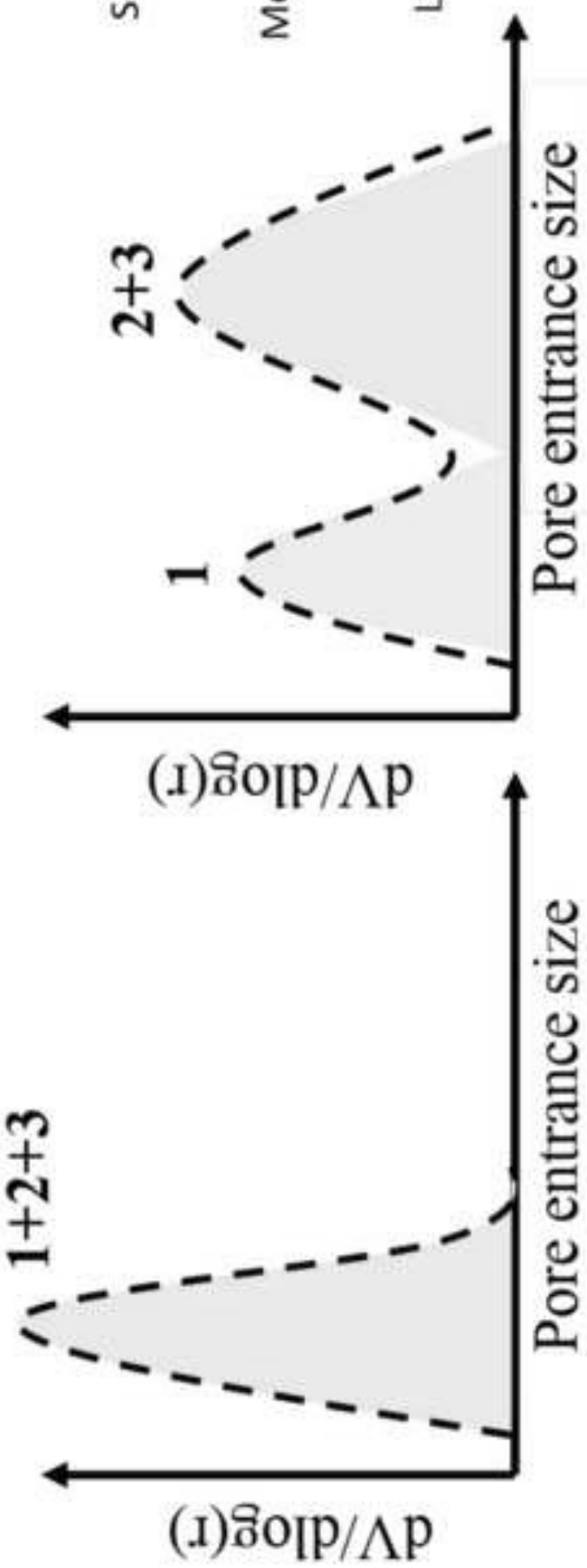

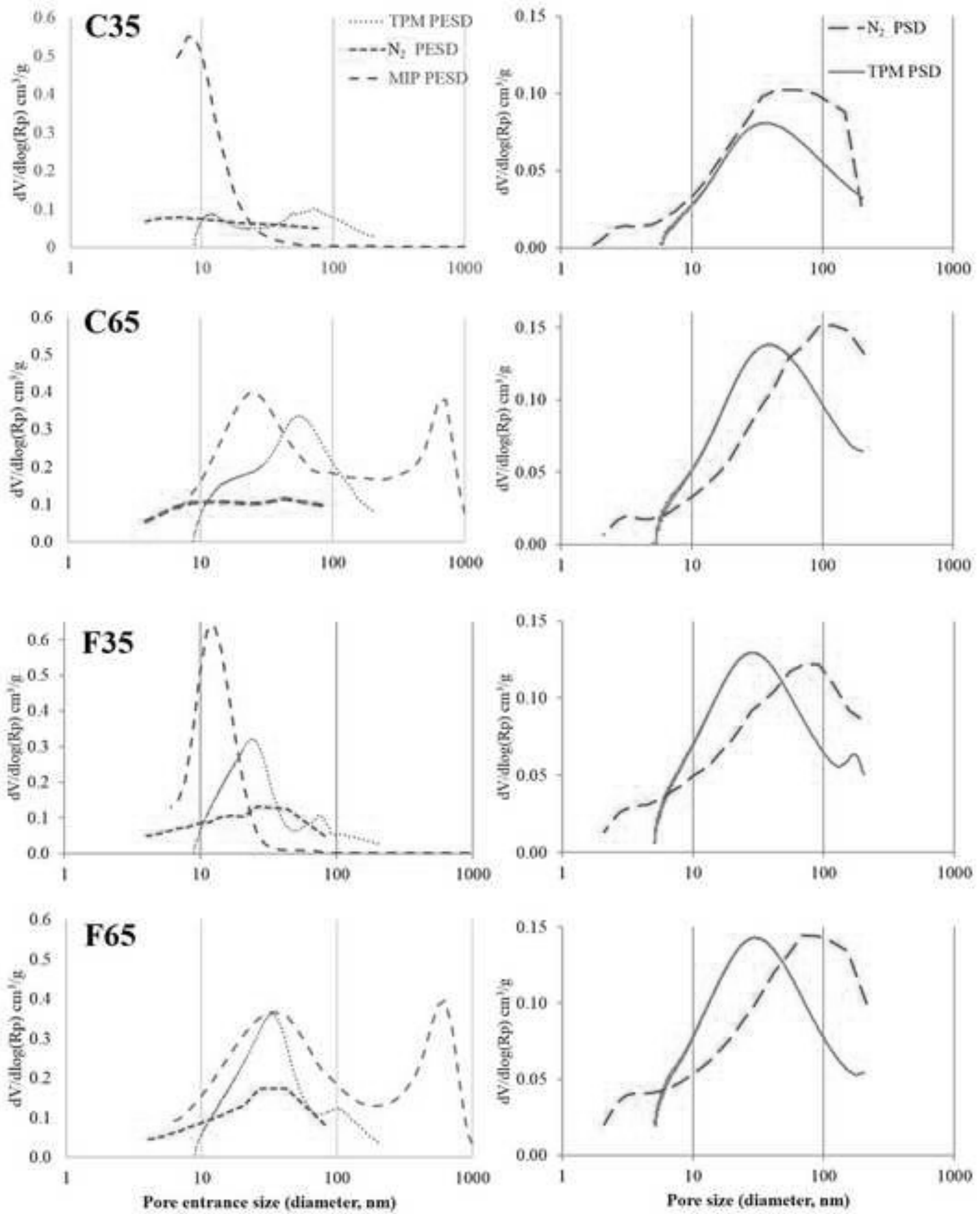

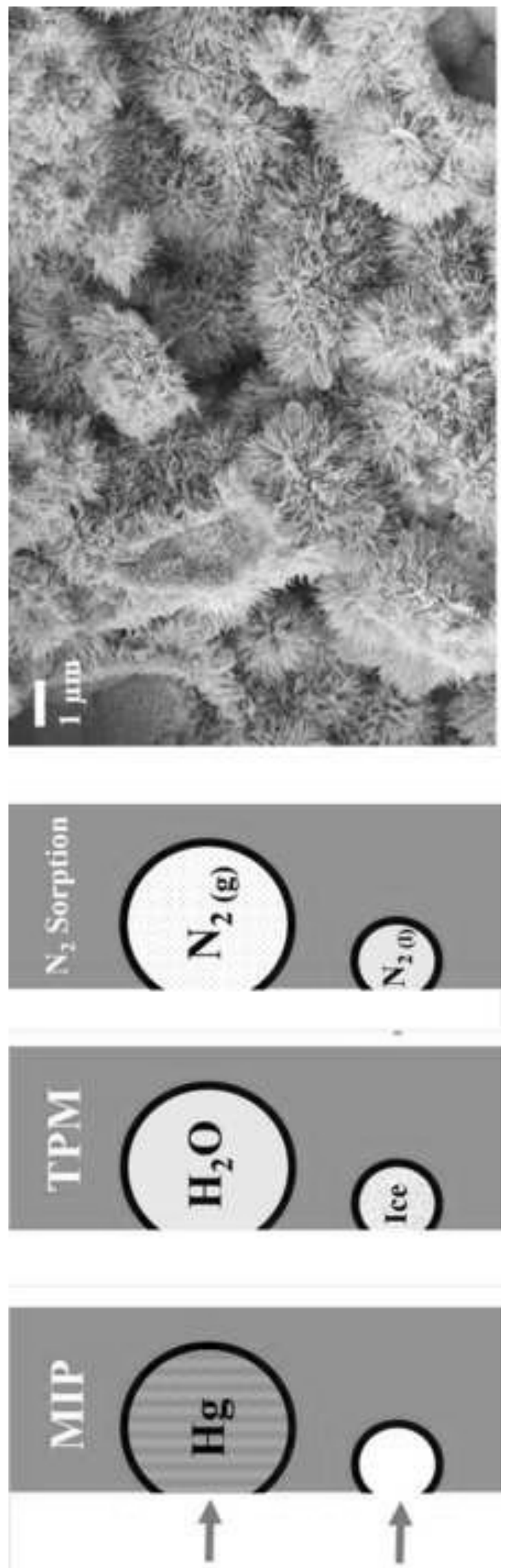